\title{
Animacy in processing relative clauses: The hikers that rocks crush
}

\author{
Willem M. Mak ${ }^{\text {a,c,*, }}$, Wietske Vonk ${ }^{\text {a,b }}$, Herbert Schriefers ${ }^{c}$ \\ ${ }^{a}$ Department of Linguistics, University of Nijmegen, The Netherlands \\ b Max Planck Institute for Psycholinguistics, Nijmegen, The Netherlands \\ ${ }^{\mathrm{c}}$ Nijmegen Institute for Cognition and Information, University of Nijmegen, The Netherlands
}

Received 11 March 2004; revision received 11 January 2006

Available online 9 March 2006

\begin{abstract}
For several languages, a preference for subject relative clauses over object relative clauses has been reported. However, Mak, Vonk, and Schriefers (2002) showed that there is no such preference for relative clauses with an animate subject and an inanimate object. A Dutch object relative clause as ...de rots, die de wandelaars beklommen hebben... ('the rock, that the hikers climbed') did not show longer reading times than its subject relative clause counterpart ...de wandelaars, die de rots beklommen hebben... ('the hikers, who climbed the rock'). In the present paper, we explore the factors that might contribute to this modulation of the usual preference for subject relative clauses. Experiment 1 shows that the animacy of the antecedent per se is not the decisive factor. On the contrary, in relative clauses with an inanimate antecedent and an inanimate relative-clause-internal noun phrase, the usual preference for subject relative clauses is found. In Experiments 2 and 3, subject and object relative clauses were contrasted in which either the subject or the object was inanimate. The results are interpreted in a framework in which the choice for an analysis of the relative clause is based on the interplay of animacy with topichood and verb semantics. This framework accounts for the commonly reported preference for subject relative clauses over object relative clauses as well as for the pattern of data found in the present experiments.
\end{abstract}

(C) 2006 Elsevier Inc. All rights reserved.

Keywords: Parsing; Topichood; Animacy; Relative clauses

\section{Processing relative clauses in Dutch: When rocks crush hikers}

When readers process a sentence, there are different types of information available to arrive at the correct interpretation of the sentence. These types of informa-

\footnotetext{
* Corresponding author. Present address: Faculty of Arts, University of Utrecht, The Netherlands.

E-mail address: pim.mak@let.uu.nl (W.M. Mak).
}

tion include the syntactic structure of the sentence, the semantic content of the words in the sentence, and pragmatic influences from the discourse in which the sentence is embedded. At any point in the sentence, the different sources of information may either work together to guide the reader towards the correct interpretation of the sentence or provide contradictory cues about the interpretation of the sentence.

This paper investigates how some of these sources of information interact in the processing of Dutch subject and object relative clauses. Examples of a subject 
relative clause and an object relative clause are given in (1) and (2), respectively.

(1) Morgen zal de professor, die de studenten ontmoet heeft, de diploma's uitreiken.

Tomorrow will the professor, that the students met has, the diplomas present.

(Tomorrow the professor, that has met the students, will present the diplomas.)

(2) Morgen zal de professor, die de studenten ontmoet hebben, de diploma's uitreiken.

Tomorrow will the professor, that the students met have, the diplomas present.

(Tomorrow the professor, that the students have met, will present the diplomas.)

The Dutch relative clauses in (1) and (2) are not disambiguated by word order, in contrast to English, but only by the number marking on the auxiliary. When the subject and the object have the same number, Dutch relative clauses with full noun phrases remain syntactically ambiguous between a subject relative clause reading and an object relative clause reading.

In studies on English and French relative clauses (e.g., Ford, 1983; Frauenfelder, Segui, \& Mehler, 1980; Holmes \& O'Regan, 1981; King \& Just, 1991; King \& Kutas, 1995; Traxler, Morris, \& Seely, 2002) it was found that object relative clauses were more difficult to process than subject relative clauses. Processing difficulty was also found at the auxiliary of verb-final relative clauses in Dutch (e.g., Frazier, 1987; Mak et al., 2002) and in German, which also has a verb-final structure in relative clauses (e.g., Mecklinger, Schriefers, Steinhauer, \& Friederici, 1995; Schriefers, Friederici, \& Kühn, 1995).

This processing difficulty at the auxiliary is still present when the thematic fit of the noun phrases with the verb (hereafter referred to as the semantic content of the verb) in the relative clause renders a subject relative clause reading very implausible, as in (3) and (4).

(3) Morgen zal de professor, die de studenten opgeleid heeft, de diploma's uitreiken.

Tomorrow will the professor, that the students educated has, the diplomas present.

(Tomorrow the professor, that has educated the students, will present the diplomas.)

(4) Morgen zullen de studenten, die de professor opgeleid heeft, de diploma's ontvangen.

Tomorrow will the students, that the professor educated has, the diplomas receive.

(Tomorrow the students, that the professor has educated, will receive the diplomas.)

In (3) and (4) the semantic content of the verb opleiden (to educate) makes it highly implausible that the noun phrase de studenten (the students) is the subject of the relative clause, and the noun phrase de professor (the professor) the object. However, experiments in German and Dutch have shown that this information did not result in the disappearance of the difference at the auxiliary: Object relative clauses, as in (4), still lead to processing difficulty on the auxiliary compared to subject relative clauses, as in (3) (Mak et al., 2002; Mecklinger et al., 1995; Schriefers et al., 1995).

Most studies mentioned above used relative clauses in which both the antecedent and the relative-clause-internal noun phrase (henceforth RC-internal noun phrase) were animate. A notable exception is a study by Traxler et al. (2002), which we will return to shortly. That the preference for subject relative clauses is modulated by the animacy of the noun phrases, has already been shown by Mak (2001; Mak et al., 2002) in selfpaced reading and eye-tracking experiments: Object relative clauses had longer reading times than subject relative clauses when both the subject and the object were animate, in line with the above-mentioned studies; the difference between subject and object relative clauses disappeared, however, when the subject of the relative clause was animate and the object inanimate, as in the subject relative clause in (5) and the object relative clause in (6).

(5) Vanwege het onderzoek moeten de inbrekers, die de computer gestolen hebben, een tijdje op het politiebureau blijven.

Because of the investigation must the burglars, that the computer stolen have, some time at the police office stay.

(Because of the investigation, the burglars, that have stolen the computer, must stay at the police office for some time.)

(6) Vanwege het onderzoek moet de computer, die de inbrekers gestolen hebben, een tijdje op het politiebureau blijven.

Because of the investigation must the computer, that the burglars stolen have, some time at the police office stay.

(Because of the investigation, the computer, that the burglars have stolen, must remain at the police office for some time.)

These data show that animacy influences relative clause processing. The data however, are open to more than one interpretation. Theories differ in the way the factor of animacy can influence parsing decisions. Syntax-first theories posit that readers begin understanding a sentence by constructing a syntactic structure based on grammatical principles. In a later stage readers use nongrammatical information to evaluate this syntactic structure. Syntax-first theories thus predict that the initial parsing decision in the processing of relative clauses is made on the basis of syntactic principles only. 
Only in a later stage of processing can this parse be affected by animacy. ${ }^{1}$

The Active Filler Strategy (Frazier, 1987) is an example of a syntax-first account. It states that when a reader encounters a filler, such as the relative pronoun, it is assigned to the earliest possible gap position, which is the subject position. Hence, readers will initially analyze a relative clause as a subject relative clause, irrespective of the semantic content of the sentence. This means that a reanalysis is necessary in every object relative clause.

Constraint-based models claim that non-syntactic information is used already in the earliest stage of processing (e.g., MacDonald, Pearlmutter, \& Seidenberg, 1994; Trueswell, Tanenhaus, \& Garnsey, 1994). In this class of models, non-syntactic information influences the initial choice between alternative structures. Trueswell et al. used animacy to manipulate the thematic fit of a sentence-initial noun phrase with the verb that followed it. This manipulation of thematic fit affected the reading times for full and reduced relative clauses. Usually, the by-phrase in reduced relative clauses as in (7) shows longer reading times than in corresponding full relative clauses. This is the case because readers prefer a main verb reading of the past participle (in (7) examined), which has to be revised on reading the by-phrase. Trueswell et al. showed that this difference between reduced relative clauses and full relative clauses disappears when the noun before the verb is improbable as the subject of the verb, as in (8).

(7) The defendant examined by the lawyer...

(8) The evidence examined by the lawyer...

Thus, in this experiment, readers were sensitive to the semantic inappropriateness of the noun as the subject of the verb, and used this information to choose the correct parse of the sentence. Trueswell et al. conclude from their experiments that semantic factors can override syntactic processing biases. However, Clifton et al. (2003) with similar sentences show that even though there is an interaction of animacy and sentence type, processing difficulty is found at the by-phrase both when the noun before the verb is animate and when it is inanimate. Clifton et al. argue that these results are consistent with a syntax-first account.Gibson (1998) discusses how the Syntactic Prediction Locality Theory can explain the difference in processing difficulty between Dutch subject and object relative clauses. He explains the preference for subject relative clauses on the basis of differences in memory load

\footnotetext{
${ }^{1} \mathrm{We}$ assume, as is common practice in the sentence processing literature (e.g., Clifton et al., 2003; Traxler et al., 2002), that animacy is semantic variable. We will return to this in General discussion.
}

between subject relative clauses and object relative clauses. According to the Syntactic Prediction Locality Theory, there is a cost associated with remembering each functional category that is required to complete the current input string as a grammatical sentence. When the reader encounters the relative pronoun, there is a difference in the number of categories to be predicted between subject relative clauses and object relative clauses. To complete the clause as a subject relative clause, two categories are necessary: a subject noun-phrase-trace and a verb. An intransitive verb would satisfy these requirements. To complete the sentence as an object relative clause, three categories need to be predicted: a subject noun phrase, an object noun-phrase-trace, and a verb. Because the parser prefers the interpretation with the fewest predicted categories, the clause is analyzed as a subject relative clause. The account of the processing of Dutch relative clauses given by the Active Filler Strategy implies that readers always choose the subject relative clause reading. In contrast to this account, the unrestricted race model (Traxler, Pickering, \& Clifton, 1998; Van Gompel, Pickering, \& Traxler, 2001; Van Gompel, Pickering, Pearson, \& Liversedge, 2005) assumes that the choice of the parser is variable. According to this model, alternative syntactic structures of an ambiguity are computed in parallel. The structure that is constructed fastest is adopted by the parser. The other possible structures are dropped, and hence when subsequent information is inconsistent with the analysis that is adopted, a reanalysis has to take place. In the case of subject and object relative clauses, this would mean that the parser sometimes analyses the clause as a subject relative clause, and in other cases as an object relative clause. The difference between subject and object relative clauses must then be the result of the fact that the subject relative clause analysis is easier to compute and hence wins the race more often than the object relative clause analysis. Traxler et al. (2002) have recently proposed that animacy is a factor that affects the relative difficulty of reanalysis. In an eye-movement experiment, Traxler et al. found longer reading times on object relative clauses as in (9b) than on corresponding subject relative clauses (9a), whereas object relative clauses as in (10b) did not have longer reading times than the corresponding subject relative clauses (10a).

(9a) The director that watched the movie received a prize at the film festival.

(9b) The director that the movie pleased received a prize at the film festival.

(10a) The movie that pleased the director received a prize at the film festival.

(10b) The movie that the director watched received a prize at the film festival.

Traxler et al. conclude from their results that "semantic factors affected how much difficulty readers had reanalyzing the sentence"' (p. 84).Coming back to the animacy 
manipulation in Mak et al. (2002), the absence of a difference between subject and object relative clauses with an animate subject and an inanimate object (see (5) and (6) above) could also be interpreted within a reanalysis account, under the assumption that a reanalysis can be made on the basis of the animacy of the antecedent. If the antecedent is inanimate, an initial interpretation of the clause as a subject relative clause, which is made at the relative pronoun, may be reanalyzed on the basis of the fact that the antecedent of the relative pronoun is inanimate. Such a reanalysis may be initiated at any point during the reading of the entire ambiguous region, which is maximally five words long (e.g., the words die de inbrekers gestolen hebben in (6)), and, therefore, does not necessarily become visible on the reading times of any of the individual words in the ambiguous region.However, the fact that there was no difference between subject and object relative clauses as in (5) and (6) is also consistent with the idea that the animacy information immediately guides the reader toward the correct syntactic analysis. In that case, no reanalysis is necessary in the object relative clauses. To decide between these alternative explanations of the data, it is necessary to explore precisely at which point in the relative clause animacy influences the parsing process. In English, this is difficult to explore, because of the difference in word order between subject and object relative clauses. In Dutch, however, subject and object relative clauses have the same word order, and hence these relative clauses provide the possibility to make a precise step by step analysis of the way in which and the point in the sentence at which animacy affects processing. In the present article, we present three experiments that make systematic use of this possibility. Most previous experiments on relative clause processing used sentences with two animate entities. In Experiment 1, we studied sentences with two inanimate entities, to investigate whether the animacy of the antecedent per se influences the parsing decision. In Experiments 2 and 3, we used sentences in which one of the noun phrases is animate, and the other inanimate, to investigate the effect of noun phrases differing in animacy on the parsing decisions.

\section{Experiment 1}

Dutch relative clauses in which both noun phrases are inanimate (see Table 1), allow testing the hypothesis that inanimate antecedents lead to a preference for an object relative clause reading.

If readers analyze the clause as an object relative clause whenever the antecedent is inanimate, both relative clauses will initially be analyzed as an object relative clause. This analysis is correct in object relative clauses (sentence B), but in subject relative clauses (sentence A) readers must reanalyze the sentence. In principle, there are two positions at which this reanalysis can be made. First, the fact that the relative-clause-internal noun phrase also is inanimate may be a cue for the reader that the initial analysis may be wrong, because both the antecedent and the relative-clause-internal noun phrase are inanimate. Second, the verb in the relative clause disambiguates the clause both syntactically (by its number marking) and semantically (by the thematic fit of the two noun phrases with the verb: only one of the noun phrases is a plausible subject of the verb), and therefore the reanalysis may be made at that position. Thus, if the inanimacy of the antecedent leads to a preference for object relative clauses, one should observe shorter reading times for object relative clauses than for subject relative clauses either at the relativeclause-internal noun phrase or at the verb.

\section{Method}

\section{Participants}

Forty students of the University of Nijmegen participated in the experiment. They were native speakers of Dutch. They were paid for their participation.

\section{Materials and design}

Sixteen sets of two sentences were constructed. An example of a set is given in Table 1. The first sentence of each set contained a subject relative clause with an inanimate subject and an inanimate object. The second sentence was the object relative clause counterpart of

Table 1

Example materials in Experiment 1

(A) Subject relative clause

Volgens de folder moet de gel, die de lekkages verhelpt, in één keer werken.

According-to the brochure must the gel, that the leakages remedies, in one time work.

According to the brochure the gel, that remedies the leakages, should work at once.

(B) Object relative clause

Volgens de folder moeten de lekkages, die de gel verhelpt, in één keer verdwenen zijn.

According-to the brochure must the leakages, that the gel remedies, in one time disappeared be.

According to the brochure the leakages, that the gel remedies, should disappear at once. 
this sentence. The object relative clauses were derived from the corresponding subject relative clauses by exchanging the antecedent noun phrase and the relative-clause-internal noun phrase. The relative clauses consisted of the sequence die de $<$ noun $><$ verb $>$. After the verb there was a comma, and after the comma there were at least three words that completed the main clause. The first two words after the comma closing the relative clause were the same in both conditions. We did not use neuter nouns, because in Dutch the form of the neuter relative pronoun (dat) is the same as the form of the complementizer.

Because inanimate entities are not likely to be the agent of an action, some of the utterances were generic. To avoid unnatural sounding sentences, the relative clauses were not in the perfect tense (contrary to the experiments in Mak et al., 2002), but in the present or the simple past. As a consequence, the relative clauses did not contain a verb cluster consisting of a past participle and an auxiliary, but a tensed main verb. ${ }^{2}$

The semantic content of the verb was such that the verb in the relative clause was consistent with only one of the nouns as the subject. The number of the verb agreed with the number of this noun. In sentences with two animate nouns, such a semantic bias of the participle did not result in an elimination of the preference for subject relative clauses at the auxiliary: Despite the semantic bias, reading times at the auxiliary were still longer for object relative clauses than for subject relative clauses (see Introduction, sentences (3) and (4)). Therefore, we did not expect an effect of a semantic bias of the verb. This is important, because such an effect of semantics could possibly override a preference that was established earlier in the relative clause.

In 8 of the items, the subject was singular and the object was plural. In the other 8 items the subject was plural and the object was singular. There was no statistically reliable difference in length between the subject nouns and the object nouns. The mean length of the subject nouns was 8.81 letters, the mean length of the object nouns was 8.19 letters: $F<1$. Also, there was no difference in frequency: The mean log frequency in the CELEX Dutch database (Baayen, Piepenbrock, \& Gulikers, 1995) was 2.47 and 3.03, respectively $(F(1,15)=1.89, p=.19)$.

An example of the layout of the sentences on the screen is shown in (11) (see Table 1, sentence A for the English translation).

\footnotetext{
${ }^{2}$ Mak, Vonk, \& Schriefers (unpublished data) showed that for sentences with two animate noun phrases, the results were similar at the auxiliary in relative clauses in the perfect tense and at the main verb in relative clauses in the simple past. The data can be obtained from the first author.
}

(11) Volgens de folder moet de gel, die de lekkages verhelpt, in één keer werken.

The first line contained the main clause up to the antecedent noun phrase; the second line contained the relative clause and the continuation of the main clause. In one item, the continuation of the main clause extended into a third line. We chose this layout in order to ensure that the entire relative clause and at least two words of the continuation of the main clause were on the same line.

In addition to the 16 experimental items there were 32 items from another experiment with relative clauses. In these relative clauses the subject and the object were both animate. There were also 42 filler sentences, which did not contain relative clauses. Just as in the experimental sentences, the first line of the filler sentences contained (part of) the main clause, and ended in a comma, as in (12).

(12) De zanger was mateloos populair bij de jeugd, maar de meeste ouders hadden een ontzettende hekel aan zijn muziek.

The singer was immensely popular with young people, but most parents detested his music awfully.

To make sure that the participants read the sentences carefully, verification statements were included after $25 \%$ of experimental and filler trials. Care was taken that the statements did not draw the attention of the participants to the experimental manipulation. The statement following the example item in Table 1 is given in (13).

(13) De folder belooft dat de behandeling in één keer zal helpen.

The brochure promises that the treatment will work at once.

The 16 experimental sentences and 74 fillers were pseudo-randomly divided into two blocks of trials. Two experimental versions were constructed. The items occurred in the same order in each version. Across the experimental versions each item occurred in each of the two conditions. The participants saw each item only once, and saw eight experimental items in each condition. Each block was preceded by six practice trials. At the beginning of the experiment there was a practice block of 14 trials. The practice items had constructions similar to the ones used in the experiment.

\section{Procedure}

The participants were tested individually. They were seated in a dimly lit room in front of a PC monitor and a panel with three buttons. They performed a selfpaced word-by-word reading task. The course of a trial was as follows. The participants saw a fixation point, 
indicating where the sentence would begin. By pushing the middle button they started the trial. The participants then saw the first word of the sentence. The letters of the other words and the commas were replaced by dashes. The full stop at the end of the sentence was visible. When the participants pressed the middle button again, the second word appeared and the first word was replaced by dashes. This was repeated until the participants had read the whole sentence. In most of the trials, the button press after the last word of the sentence was followed by the fixation point announcing the next trial. In $25 \%$ of the trials, however, the participants saw the word bewering (statement) for $1 \mathrm{~s}$, followed by a verification statement about the sentence. The participants had to judge whether this statement was consistent with the content of the sentence they had just read. If it was consistent, they had to press the right button, if not they had to press the left button.

\section{Results}

Reading times shorter than $50 \mathrm{~ms}$ and longer than $4000 \mathrm{~ms}$ ( 1 case) were excluded from further analysis. From the remaining reading times those that were more than two standard deviations away from a participant's and item's mean for a given position in a condition (121 cases) were excluded (1.4\% of the data points). Participants read the verification statements carefully: On average, they gave the correct answer to $93 \%$ of these statements (lowest score 83\%, standard deviation 5\%).

Fig. 1 presents the mean reading times as a function of the type of relative clause for all word positions from the verb of the main clause up to and including two words after the verb of the relative clause. For each position presented in Fig. 1, two one-way analyses of variance were computed, one with participants $(F 1)$ and

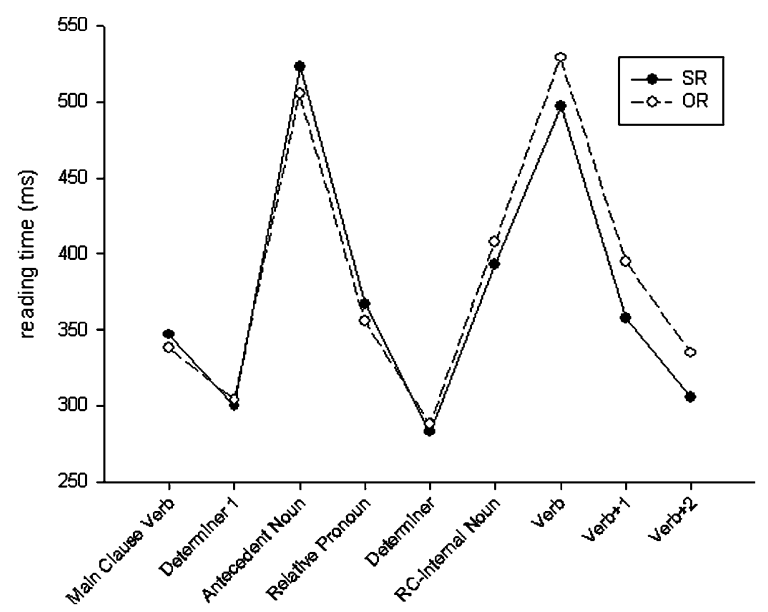

Fig. 1. Mean reading times (in $\mathrm{ms}$ ) in Experiment 1 as a function of Clause Type. SR, subject relative clause; OR, object relative clause. one with items $(F 2)$ as a the random variable. We also computed $\min F^{\prime}$ (Clark, 1973; Raaijmakers, Schrijnemakers, \& Gremmen, 1999). Clause Type (subject relative clause vs. object relative clause) was the factor in the analyses. The theoretically important differences in this and subsequent experiments were evaluated using pairwise contrasts. We calculated $95 \%$ confidence intervals for differences between two means, which were calculated from the mean square errors from the relevant main effects (Experiment 1) or interactions (Experiments 2 and 3 ) in the analysis of variance by participants (Masson \& Loftus, 2003). When the size of the halfwidth of the confidence interval does not exceed the difference between the means the difference between the means is significant at the .05 level. The results of the statistical tests for the disambiguating verb and the two words following it are presented in Table 2. In the following, we will discuss the effects that were significant in the participant and item analyses.

There was no effect at any position preceding the disambiguating verb. At the disambiguating verb in the relative clause, reading times were $32 \mathrm{~ms}$ longer in the object relative clauses than in the subject relative clauses. However, this difference was not significant, with a $95 \%$ confidence interval of $\pm 48 \mathrm{~ms}$. At the first word after the disambiguating verb object relative clauses were read significantly slower than subject relative clauses ( $395 \mathrm{~ms}$ vs. $358 \mathrm{~ms}$ ). The $95 \%$ confidence interval for this $37 \mathrm{~ms}$ difference was $\pm 25 \mathrm{~ms}$. At the second word after the disambiguating verb, reading times were again significantly longer in object relative clauses than in subject relative clauses ( $335 \mathrm{~ms}$ vs. $306 \mathrm{~ms}$ ). The $95 \%$ confidence interval for this $29 \mathrm{~ms}$ difference was $\pm 15 \mathrm{~ms}$.

\section{Discussion}

Experiment 1 was designed to test the hypothesis that readers have a preference for an object relative clause when the antecedent is inanimate. In that case, reading times should have been longer for subject relative clauses than for object relative clauses at the relative-clause-internal noun phrase or at the clause-final verb. However, there was no such effect at the relative-clause-internal noun phrase. Rather, an effect was found at the words following the clause-final verb, and it was in the opposite direction, showing that readers prefer a subject relative clause when both the antecedent and the relativeclause-internal noun phrase are inanimate. Thus, for these relative clauses the preferences are the same as for relative clauses with two animate noun phrases.

Mak et al. (2002) found that there is no processing difficulty in object relative clauses with an inanimate antecedent and an animate relative-clause-internal noun phrase (e.g., (6), above). Experiment 1 shows that this result cannot be explained by a simple strategy in which readers analyze the clause as a subject relative clause 
Table 2

Analysis of variance results of Experiment 1

\begin{tabular}{|c|c|c|c|c|c|c|c|}
\hline \multirow[t]{2}{*}{ Region } & \multirow[t]{2}{*}{ Source of variance } & \multicolumn{2}{|c|}{ By participants } & \multicolumn{2}{|c|}{ By items } & \multicolumn{2}{|c|}{$\operatorname{Min} F^{\prime}$} \\
\hline & & $d f$ & $F 1$ & $d f$ & $F 2$ & $d f$ & $\min F^{\prime}$ value \\
\hline disamb & Clause Type & 1,39 & 1.91 & 1,15 & 0.39 & 1,21 & 0.32 \\
\hline disamb +1 & Clause Type & 1,39 & $8.59^{* *}$ & 1,15 & $5.17^{*}$ & 1,34 & $3.23^{\dagger}$ \\
\hline disamb +2 & Clause Type & 1,39 & $14.03^{* *}$ & 1,15 & $13.60^{* *}$ & 1,43 & $6.91^{*}$ \\
\hline
\end{tabular}

Note. disamb, disambiguating verb; disamb +1 , first word following disambiguating verb; disamb +2 , second word following the disambiguating verb.

$\begin{array}{rl}{ }^{*} & p<.05 . \\ & { }^{*} p<.01 . \\ & p<.10\end{array}$

when the antecedent is animate and as an object relative clause when the antecedent is inanimate. If this would have been the case, readers should have opted for an object relative clause in both conditions of Experiment 1, which should eventually have led to longer reading times in the subject relative clauses than in the object relative clauses. Experiment 1 actually showed the reverse result, i.e., longer reading times in object relative clauses than in subject relative clauses. Hence, the modulation of the subject preference by animacy seems to depend on a difference in animacy between the two noun phrases involved in the relative clause. This information does not become available before the relative-clause-internal noun phrase.

As mentioned in Materials and design, the verbs and nouns were selected such that the semantic content of the verb was consistent with only one of the nouns as the subject, and the number of the verb always agreed with the number of that noun. In principle, the semantic bias of the verb could thus override a preference that was established earlier in the relative clause. Nevertheless, in the present experiment we did observe a preference for subject relative clauses. This is consistent with the results in similar Dutch sentences with two animate noun phrases (e.g., Mak et al., 2002). We will return to the issue of verb semantics in the introduction to Experiment 2.

Mak et al. (2002) found that in relative clauses with an animate subject and an inanimate object, there was no difference in processing times between subject and object relative clauses. In Introduction, two explanations for these data were given.

The first explanation was that readers do opt for a subject relative clause in all cases, and have to make a reanalysis in an object relative clause. This reanalysis is affected by the animacy of the noun phrases. Hence, readers may make the reanalysis in the entire relative clause region. Because this reanalysis may be spread over several words it is not necessarily visible in the reading times. To evaluate this explanation it is important to see at what point animacy influences the parsing process. Experiment 1 shows that the influence of animacy must be due to the difference in animacy between the two noun phrases. Thus, animacy can only begin to play a role at the relative-clause-internal noun. This implies that the region at which a reanalysis could be made for the sentences used by Mak et al. (2002) is reduced to maximally three words: the relative-clause-internal noun, the past participle and the auxiliary. Still, one could argue that a reanalysis that can be initiated at any point in this region of three words does not have to be visible in the reading times.

The alternative explanation is that animacy guides the initial interpretation of the relative clause. In Experiments 2 and 3, we further explore at which point in the relative clause animacy influences the parsing process. Given the results of Experiment 1, one could hypothesize that the choice for an analysis is driven by the competition between different noun phrases for a syntactic function. After having read the relative-clause-internal noun phrase, the reader has available two candidate noun phrases for the syntactic functions of subject and object. The assignment of syntactic functions to the two noun phrases may then be based on the animacy of the two noun phrases. If the candidates for the syntactic function of subject are an animate and an inanimate noun phrase, the animacy of the two noun phrases may be one of the factors that determine the assignment of the subject function. Because the animate noun phrase better fits the subject role than the inanimate noun phrase, readers may assign this role to the animate noun phrase rather than to the inanimate noun phrase.

Apart from animacy, there is another factor that must be taken into consideration when studying relative clause processing: Since the relative clause is a statement about the antecedent, the antecedent is the topic of the relative clause (cf. Kuno, 1976; Lambrecht, 1988; Van Valin, 1996). Since there is a tendency for the topic to be the subject of a clause, we hypothesize that the antecedent will be chosen as the subject, other influences on the choice of the subject of the relative clause being equal. This would explain the preference for subject relative clauses in sentences in which the antecedent 
noun phrase and the relative-clause-internal noun phrase are equal in animacy.

In Experiments 2 and 3, we will investigate the influence of animacy and topichood. In General discussion we will discuss these factors in the light of a more general theory of relative clause processing.

\section{Experiment 2}

Given the considerations in the discussion of Experiment 1 , there are two potential factors that may affect the assignment of the syntactic function of subject and object in relative clauses with two full noun phrases: the preference for the antecedent noun phrase as the subject of the relative clause, and the preference for animate noun phrases as the subject of the relative clause. In Experiment 2, we investigated the influence of these two factors on relative clause processing. We used relative clauses with an animate and an inanimate entity. The first factor in the experiment was Animacy of Subject: Either the animate or the inanimate entity was the subject of the relative clause. The other factor was Clause Type: the clause was either a subject relative clause or an object relative clause. Table 3 presents an example item in the four experimental conditions and describes how the two factors were contrasted in the experimental sentences.

On reading the relative-clause-internal noun phrase of sentences with an animate antecedent noun phrase and an inanimate relative-clause-internal noun phrase (conditions SubjRC-Animate Subject and
ObjRC-Inanimate Subject), the two factors work together to put forward the animate antecedent noun phrase as the subject of the relative clause: The relative pronoun is a potential subject both because of the topicality of the antecedent and because of the fact that the antecedent is animate. When the factors are in agreement with each other, readers could use this information to assign the syntactic functions of subject and object to the two noun phrases immediately on reading the relative-clause-internal noun phrase, thus analyzing the clause as a subject relative clause. When the sentence indeed turns out to be a subject relative clause (condition SubjRC-Animate Subject), there is no processing problem, but when the sentence turns out to be an object relative clause (condition ObjRC-Inanimate Subject), a reanalysis must be made.

In sentences with an inanimate antecedent noun phrase and an animate relative-clause-internal noun phrase (conditions ObjRC-Animate Subject and SubjRC-Inanimate Subject), however, the two factors work against each other at the relative-clause-internal noun phrase. The relative pronoun is a potential subject because of the topicality of the antecedent, and the relative-clause-internal noun phrase is a potential subject because it is animate. Thus, the reader is confronted with contradictory evidence at the relative-clause-internal noun phrase. We hypothesize that, in this situation, the reader will postpone the assignment of syntactic functions to the two noun phrases. The eventual assignment can then be made either on the basis of the number marking on the auxiliary or on the basis of the semantic content of the verb. The latter possibility appears, at first

Table 3

Example materials in Experiments 2 and 3

Subject relative clause, Animate subject (SubjRC-Animate Subject)

(i.e., animate antecedent, and inanimate RC-internal NP)

In het dorp zijn de wandelaars, die de rots weggerold hebben, het gesprek van de dag.

In the town are the hikers, that the rock rolled-away have, the talk of the day.

"In the town the hikers, that have rolled away the rock, are the talk of the day."

Object relative clause, Animate subject (ObjRC-Animate Subject)

(i.e., inanimate antecedent, animate RC-internal NP)

In het dorp is de rots, die de wandelaars weggerold hebben, het gesprek van de dag.

In the town is the rock, that the hikers rolled-away have, the talk of the day.

"In the town the rock, that the hikers have rolled away, is the talk of the day."

Subject relative clause, Inanimate subject (SubjRC-Inanimate Subject)

(i.e., inanimate antecedent, animate RC-internal NP)

In het dorp is de rots, die de wandelaars verpletterd heeft, het gesprek van de dag.

In the town is the rock, that the hikers crushed has, the talk of the day.

"In the town the rock, that has crushed the hikers, is the talk of the day."

Object relative clause, Inanimate subject (ObjRC-Inanimate Subject)

(i.e., animate antecedent, inanimate RC-internal NP)

In het dorp zijn de wandelaars, die de rots verpletterd heeft, het gesprek van de dag.

In the town are the hikers, that the rock crushed has, the talk of the day.

"In the town the hikers, that the rock has crushed, are the talk of the day." 
sight, to be ruled out by the findings for sentences with two animate noun phrases (Mak et al., 2002) and sentences with two inanimate noun phrases (Experiment 1), which did not show an effect of the semantic content of the verb. However, in the present situation the chance to observe an effect of the semantic content of the verb might be larger than in previous studies, for the following reason: We assume that in sentences with an inanimate antecedent and an animate relative-clause-internal noun phrase (ObjRC-Animate Subject and SubjRC-Inanimate Subject) no commitment has been made before reading the verb in the relative clause, because topicality of the antecedent and animacy work against each other. Therefore, the semantic content of the verb would not have to override a decision that has already been taken, but rather can be used to arrive at a decision that could not have been taken before because of conflicting evidence from animacy and topicality of the antecedent.

Taken together, we arrive at the following scenario. In conditions SubjRC-Animate Subject, ObjRC-Animate Subject, and SubjRC-Inanimate Subject, the relative clause will be analyzed correctly, and no reanalysis will be necessary. However, in condition ObjRC-Inanimate Subject, the relative clause is analyzed as a subject relative clause at the relative-clause-internal noun phrase, and therefore readers do have to make a reanalysis, either on the basis of the semantic content of the verb, or on the basis of the number marking at the auxiliary.

If this account is correct, in terms of the design used in this experiment there should be no difference in reading times between the conditions with an animate subject (SubjRC-Animate Subject and ObjRC-Animate Subject), in line with the results of Mak et al. (2002). However, in the conditions with an inanimate subject, the object relative clause (condition ObjRC-Inanimate Subject) should show longer reading times than the subject relative clause (condition SubjRC-Inanimate Subject). Thus, we would expect an interaction of Animacy of Subject (animate vs. inanimate) and Clause Type (subject relative clause vs. object relative clause). Note that the design is such, that the comparison between SubjRC-Animate Subject and ObjRC-Animate Subject on the one hand, and SubjRC-Inanimate Subject and ObjRC-Inanimate Subject on the other hand is a comparison that is made between precisely the same nouns and verbs, so that any difference in these comparisons cannot be due to lexical differences.

\section{Method}

\section{Participants}

Thirty-two students of the University of Nijmegen participated in the experiment. They were native speakers of Dutch. They were paid for their participation. They had not participated in Experiment 1.

\section{Materials and design}

Thirty-two sets of four sentences were constructed. An example of a set of sentences is given in Table 3 . The first sentence (condition SubjRC-Animate Subject) of each set contained a subject relative clause with an animate subject, and, therefore, an animate antecedent. The second sentence (condition ObjRC-Animate Subject) was the object relative clause counterpart of this sentence: It had an animate subject but the antecedent was inanimate. It was derived by exchanging the antecedent noun phrase and the relative-clause-internal noun phrase. The third sentence (condition SubjRC-Inanimate Subject) contained a subject relative clause with an inanimate subject, and, therefore, an inanimate antecedent. The fourth sentence (condition ObjRC-Inanimate Subject) was the object relative clause counterpart of the third sentence: It had an inanimate subject, but the antecedent was animate. The relative clauses contained a verb cluster consisting of a past participle and an auxiliary.

The relative clauses consisted of the sequence die de $<$ noun $><$ past participle $><$ auxiliary $>$. After the auxiliary there was a comma, and after the comma there were at least three words that completed the main clause. At least the first two words after the comma closing the relative clause were the same in all conditions. Note, that also the relative pronouns and the determiners were identical in all four conditions.

In 16 of the items, the subject was singular and the object was plural. In the other 16 items the subject was plural and the object was singular. The mean length of the animate nouns was 8.59 letters, the mean length of the inanimate nouns was 8.47 letters. This difference was not statistically significant: $F<1$. The mean log frequency in the CELEX Dutch database was 3.06 for the animate nouns and 2.70 for the inanimate nouns. This difference was not significant either $(F(1,31)=2.17$, $p=.15)$. The mean length of the past participles in the animate subject condition and the inanimate subject condition was 8.31 letters and 9.38 letters, respectively. This difference was significant: $F(1,31)=7.28, p<.05$. The past participles in the animate subject condition were more frequent than the past participles in the inanimate subject condition: the mean log frequency was 3.14 and 2.53 , respectively $(F(1,31)=16.68, p<.001)$. Due to the fact that we selected the inanimate nouns such that they could not be interpreted as animate (which would be the case with the noun committee, for example), the choice of past participles that could have the inanimate nouns as the subject was very limited. This difference in length and frequency is problematic for the interpretation of a main effect of the animacy of the subject. However, the crucial prediction of the experiment is an interaction that cannot be due to these differences: There should be no difference between sentences with animate subjects (SubjRC-Animate Subject and ObjRC-Animate Subject), whereas in the conditions with an inanimate 
subject (SubjRC-Inanimate Subject and ObjRC-Inanimate Subject) object relative clauses should have longer reading times than subject relative clauses.

As already indicated above, not only the number marking on the auxiliary, but also the semantic content of the past participle can potentially be used by the reader to determine their analysis of the relative clause. The semantic content of the past participle in the relative clause was consistent with the correct syntactic analysis of the relative clause: The verb in the relative clause was consistent with only one of the nouns as the subject and the number of the auxiliary agreed with the number of this noun. Thus, using the semantic information of the past participle information would lead the reader to a choice of the correct analysis of the relative clause.

An example of the layout of the sentences on the screen is shown in (14) (see Table 3, SubjRC-Animate Subject, for the English translation).

(14) In het dorp zijn de wandelaars, die de rots weggerold hebben, het gesprek van de dag.

The first line contained the main clause up to the antecedent noun phrase; the second line contained the relative clause and at least two words of the continuation of the main clause. Some of the items continued on the third line.

The 32 experimental items were mixed with 42 unrelated filler sentences. The filler sentences were the same as in Experiment 1.

To make sure that the participants read the sentences carefully, verification statements were included after $25 \%$ of experimental and filler trials. Care was taken that the statements did not draw the attention of the participants to the experimental manipulation. An example of an item and statement is given in (15).

(15) Bij de collega's heeft de wetenschapper, die de theorieën ontwikkeld heeft, grote beroering veroorzaakt.

Er was grote beroering onder de collega's.

Amongst the colleagues the scientist, that has developed the ideas, has caused a lot of commotion.

There was a lot of commotion amongst the colleagues.

The 32 experimental items and 42 fillers were pseudorandomly divided into two blocks of trials. Four experimental versions were constructed. The items occurred in the same order in each version. Across the experimental versions each item occurred in every condition. The participants saw each item only once, and saw eight experimental items in each condition. At the beginning of the experiment there was a practice block of 14 trials. The practice items had constructions similar to the ones used in the experiment.

\section{Procedure}

The procedure was the same as in Experiment 1.

\section{Results}

Reading times shorter than $50 \mathrm{~ms}$ and longer than $4000 \mathrm{~ms}$ ( 15 cases) were excluded from further analysis. From the remaining reading times those that were more than two standard deviations away from a participant's and item's mean for a given position in a condition (192 cases) were excluded $(1.3 \%$ of the data points). Participants read the verification statements carefully: On average, they gave the correct answer to $90 \%$ of these statements (lowest score $73 \%$, standard deviation $6 \%$ ).

Fig. 2 presents the mean reading times as a function of the type of relative clause and the animacy of the subject for all word positions from the verb of the main clause up to and including two words after the auxiliary. For each position presented in Fig. 2, two two-way analyses of variance were computed, one with participants $(F 1)$ and one with items $(F 2)$ as the random variable. Animacy of Subject (animate subject vs. inanimate subject) and Clause Type (subject relative clause vs. object relative clause) were the factors in the analyses. The results of the statistical tests for the critical regions are presented in Table 4. In the following, we will discuss the effects that were significant in the participant and item analyses.

At the relative-clause-internal noun there was a significant interaction of Animacy of Subject and Clause Type. This interaction is due to the animacy of the relative-clause-internal noun. Inanimate nouns were read

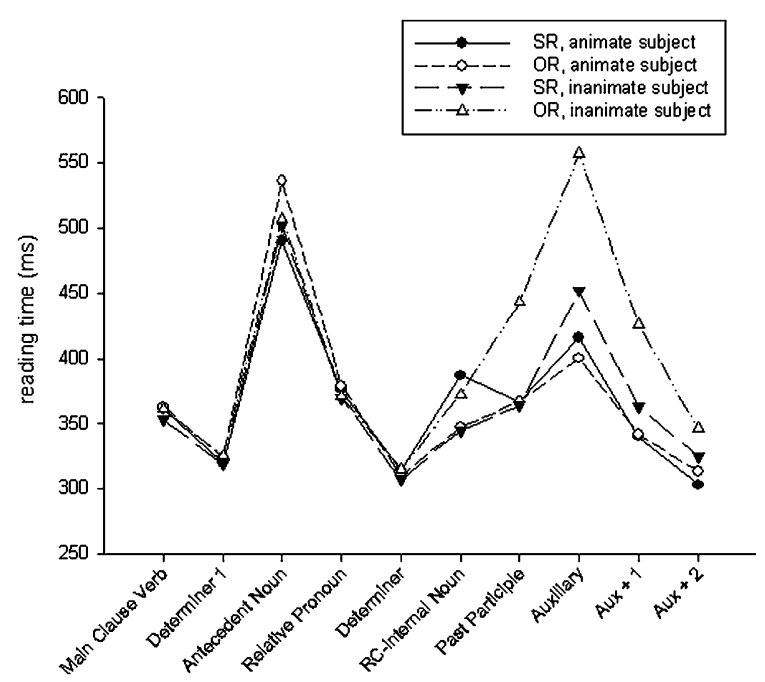

Fig. 2. Mean reading times (in $\mathrm{ms}$ ) in Experiment 2 as a function of Clause Type and animacy of subject. SR, subject relative clause; OR, object relative clause. 
Table 4

Analysis of variance results of Experiment 2

\begin{tabular}{|c|c|c|c|c|c|c|c|}
\hline \multirow[t]{2}{*}{ Region } & \multirow[t]{2}{*}{ Source of variance } & \multicolumn{2}{|c|}{ By participants } & \multicolumn{2}{|c|}{ By items } & \multicolumn{2}{|c|}{$\operatorname{Min} F^{\prime}$} \\
\hline & & $d f$ & $F 1$ & $d f$ & $F 2$ & $d f$ & $\min F^{\prime}$ \\
\hline \multirow[t]{3}{*}{ Antecedent noun } & Animacy & 1,31 & .50 & 1,31 & .78 & 1,59 & .30 \\
\hline & Clause Type & 1,31 & 1.76 & 1,31 & $3.96^{\dagger}$ & 1,54 & 1.21 \\
\hline & Animacy $\times$ Clause Type & 1,31 & 1.54 & 1,31 & .28 & 1,42 & .24 \\
\hline \multirow[t]{3}{*}{ RC-internal noun } & Animacy & 1,31 & .68 & 1,31 & 1.47 & 1,55 & .46 \\
\hline & Clause Type & 1,31 & .42 & 1,31 & .40 & 1,62 & .20 \\
\hline & Animacy $\times$ Clause Type & 1,31 & $11.89^{* *}$ & 1,31 & $12.08^{* *}$ & 1,62 & $5.99^{*}$ \\
\hline \multirow[t]{3}{*}{ Past participle } & Animacy & 1,31 & $5.91^{*}$ & 1,31 & $4.50^{*}$ & 1,61 & 2.55 \\
\hline & Clause Type & 1,31 & $4.58^{*}$ & 1,31 & $5.15^{*}$ & 1,62 & 2.42 \\
\hline & Animacy $\times$ Clause Type & 1,31 & $5.75^{*}$ & 1,31 & $9.45^{* *}$ & 1,59 & $3.57^{\dagger}$ \\
\hline \multirow[t]{3}{*}{ Auxiliary } & Animacy & 1,31 & $22.72^{* *}$ & 1,31 & $23.88^{* *}$ & 1,62 & $11.65^{* *}$ \\
\hline & Clause Type & 1,31 & $4.15^{*}$ & 1,31 & $3.11^{\dagger}$ & 1,61 & 1.78 \\
\hline & Animacy $\times$ Clause Type & 1,31 & $8.58^{* *}$ & 1,31 & $6.92^{*}$ & 1,61 & $3.83^{\dagger}$ \\
\hline \multirow[t]{3}{*}{ Auxiliary +1} & Animacy & 1,31 & $38.34^{* *}$ & 1,31 & $26.24^{* *}$ & 1,60 & $15.57^{* *}$ \\
\hline & Clause Type & 1,31 & $15.42^{* *}$ & 1,31 & $10.42^{* *}$ & 1,60 & $6.22^{*}$ \\
\hline & Animacy $\times$ Clause Type & 1,31 & $11.34^{* *}$ & 1,31 & $8.78^{* *}$ & 1,61 & $4.95^{*}$ \\
\hline \multirow{3}{*}{ Auxiliary +2} & Animacy & 1,31 & $12.78^{* *}$ & 1,31 & $10.02^{* *}$ & 1,61 & $5.62^{*}$ \\
\hline & Clause Type & 1,31 & 2.20 & 1,31 & $3.12^{\dagger}$ & 1,60 & 1.29 \\
\hline & Animacy $\times$ Clause Type & 1,31 & .04 & 1,31 & .01 & 1,46 & .01 \\
\hline
\end{tabular}

${ }^{*} p<.05$.

$p<.01$.

$\dagger p<.10$.

more slowly than animate nouns, both in the conditions with an animate subject ( $387 \mathrm{~ms}$ vs. $347 \mathrm{~ms}$ ) and in the conditions with an inanimate subject $(372 \mathrm{~ms}$ vs. $345 \mathrm{~ms}$ ). The $95 \%$ confidence interval for these 40 and $27 \mathrm{~ms}$ differences was $\pm 21 \mathrm{~ms}$.

At the past participle there were main effects of Animacy of Subject and Clause Type. Importantly, these main effects were qualified by a significant interaction of Animacy of Subject and Clause Type. In the conditions with an inanimate subject, the past participles in object relative clauses (condition ObjRC-Inanimate Subject; $443 \mathrm{~ms}$ ) had longer reading times than those in subject relative clauses (condition SubjRC-Inanimate Subject; $364 \mathrm{~ms}$ ). The 95\% confidence interval of this $79 \mathrm{~ms}$ difference was $\pm 25 \mathrm{~ms}$. In the conditions with an animate subject (SubjRCAnimate Subject and ObjRC-Animate Subject), however, there was no effect of Clause Type (both means $367 \mathrm{~ms})$.

At the auxiliary there was a main effect of Animacy of Subject, a main effect of Clause Type, and an interaction of Animacy of Subject and Clause Type. In the conditions with an inanimate subject (conditions SubjRC-Inanimate Subject and ObjRC-Inanimate Subject) object relative clauses were read more slowly than subject relative clauses ( $557 \mathrm{~ms}$ vs. $452 \mathrm{~ms}$ ). In the conditions with an animate subject (conditions SubjRCAnimate Subject and ObjRC-Animate Subject) there was no difference in reading times between object and subject relative clauses (400 and $416 \mathrm{~ms}$, respectively). The $95 \%$ confidence interval was $\pm 38 \mathrm{~ms}$.
At the first word after the auxiliary, too, there was a main effect of Animacy of Subject, a main effect of Clause Type, and an interaction of Animacy of Subject and Clause Type. Again, in the conditions with an inanimate subject (conditions SubjRC-Inanimate Subject and ObjRC-Inanimate Subject) object relative clauses were read more slowly than subject relative clauses (426 ms vs. $363 \mathrm{~ms}$ ). In the conditions with an animate subject (conditions SubjRC-Animate Subject and ObjRC-Animate Subject) there was no difference in reading times between object and subject relative clauses (342 and $340 \mathrm{~ms}$, respectively). The 95\% confidence interval was $\pm 17 \mathrm{~ms}$.

At the second word after the auxiliary there was a main effect of Animacy of Subject. At this position, there were no other main effects or interactions.

At other positions in the sentence, there were no main effects or interactions.

\section{Discussion}

Experiment 2 reveals an interaction of Animacy of Subject and Clause Type at the past participle, the auxiliary and at the word following the auxiliary. In the conditions with an animate subject (conditions SubjRC-Animate Subject and ObjRC-Animate Subject), there is no difference in reading times between subject and object relative clauses at the past participle, the auxiliary, and the word following the auxiliary. In the conditions with an inanimate subject (conditions SubjRC-Inanimate Subject and 
ObjRC-Inanimate Subject), however, at these same positions, reading times are longer in the object relative clauses than in subject relative clauses.

In the discussion of Experiment 1, we concluded that the inanimacy of the antecedent by itself does not lead to a reanalysis, and hence a possible reanalysis is not made before the relative-clause-internal noun is read. The region at which a reanalysis can be made, is then only three words long, for instance in (6), repeated here as (16), inbrekers gestolen hebben.

(16) Vanwege het onderzoek moet de computer, die de inbrekers gestolen hebben, een tijdje op het politiebureau blijven.

Because of the investigation must the computer, that the burglars stolen have, some time at the police office stay.

(Because of the investigation, the computer, that the burglars have stolen, must remain at the police office for some time.)

Readers may make a reanalysis on the basis of the fact that the antecedent noun is inanimate and the relative-clause-internal noun phrase is animate. However, on the basis of the results of Experiment 2, one can conclude that having an inanimate antecedent, and an animate relative-clause-internal noun phrase, as is the case in (16), does not by itself lead to a reanalysis of the sentence. If that were the case, prolonged reading times should be found at or after the relative-clause-internal noun phrase when it is animate. This should hold for the comparison of conditions SubjRC-Animate Subject and ObjRC-Animate Subject with ObjRC-Animate Subject being slower than SubjRC-Animate Subject at the relative-clause-internal noun phrase and/or the next word. It should also hold for the comparison of SubjRC-Inanimate Subject and ObjRC-Inanimate Subject, with SubjRC-Inanimate Subject being more difficult than ObjRC-Inanimate Subject. The data do not support this. In fact, the difference between SubjRC-Animate Subject and ObjRC-Animate Subject is not even descriptively in the predicted direction, and for conditions SubjRC-Inanimate Subject and ObjRC-Inanimate Subject, ObjRC-Inanimate Subject turns out to be more difficult than SubjRC-Inanimate Subject, in the region from the past participle up to the word following the auxiliary. Hence, a reanalysis apparently is not started at the relative-clause-internal noun. Therefore, the region at which the reanalysis can be made in (16) is reduced to only two words, the VP gestolen hebben. It is extremely unlikely that such a reanalysis would not be visible in the data. In fact, in the sentences with an animate subject in Experiment 2, reading times in this region are equal at the past participle and even numerically faster in the object relative clauses than in the subject relative clauses at the auxiliary. Therefore, an account of the data in terms of a semantically driven reanalysis of an initial syntactic analysis is not supported by the data.

The results can be explained, however, by the simultaneous effect of two factors on the selection of the subject of the relative clause. First, on the basis of topicality of the antecedent readers prefer the relative pronoun to be the subject of the relative clause. Second, readers prefer animate entities over inanimate entities as the subject of the relative clause. We argued in the discussion of Experiment 1 that the earliest position at which a difference in animacy can affect the interpretation of the clause is at the relative-clause-internal noun phrase. We hypothesized that, on reading the relative-clause-internal noun phrase, readers assign the subject and object functions, if the factors that govern this assignment are in agreement with each other. When the factors are contradictory, readers will postpone their decision until more information becomes available and assign the subject and object functions on the basis of this information.

In the relative clauses with an animate subject and an inanimate object, the following applies: In subject relative clauses (condition SubjRC-Animate Subject) the animate noun phrase is the antecedent. Hence both factors put forward the animate noun phrase as the subject and the reader correctly assigns it the subject function. In the object relative clauses (condition ObjRC-Animate Subject), in which the inanimate noun phrase is the antecedent, the factors are contradictory, and hence the reader postpones the assignment of subject and object functions. The assignment is then made either on the basis of the semantic content of the verb, or on the basis of the number marking of the auxiliary. Both sources of information lead to the (correct) assignment of the object function to the inanimate antecedent noun phrase. Therefore, no processing difficulty is found in either the subject or the object relative clause.

In the relative clauses with an inanimate subject and an animate object, the following applies: In the subject relative clauses (condition SubjRC-Inanimate Subject) the antecedent is inanimate. Hence, the situation at the relative-clause-internal noun phrase is the same as in the object relative clauses in condition ObjRC-Animate Subject. Here, also, the factors are contradictory, and hence the assignment of subject and object functions is postponed. Again, on the basis of information from either the past participle or the auxiliary, the correct assignment of the subject function is made, in this case to the inanimate noun phrase. In the object relative clauses (condition ObjRC-Inanimate Subject), as in condition SubjRC-Animate Subject, the animate noun phrase is the antecedent. Hence both factors put forward the animate noun phrase as the subject and the reader assigns it the subject function. However, on reading the verb cluster both the semantic content of the past participle and the number marking on the auxiliary 
show that this analysis is incorrect, and hence a reanalysis has to be made, which leads to longer reading times in this condition, compared to condition SubjRC-Inanimate Subject.

Note that the reading times already diverge at the past participle. This has not been shown before in experiments on Dutch and German relative clauses. In our framework, the early divergence of reading times in conditions SubjRC-Inanimate Subject and ObjRC-Inanimate Subject can be interpreted in two ways. First, because of the opposing two factors in condition SubjRC-Inanimate Subject (topicality of the antecedent vs. animacy difference with inanimate antecedent) readers do not make a commitment before reading the past participle, and thus on the basis of the semantic content of the past participle the correct analysis can quite easily be selected and reading times are short. Second, in condition ObjRC-Inanimate Subject, both factors speak in favor of an analysis of the clause as a subject relative clause. If this analysis is made on reading the relativeclause-internal noun phrase, this analysis has to be revised on reading the past participle, which leads to long reading times at the past participle. The effect observed at the past participle could be due to any kind of mixture of these two accounts. Actually, it might be precisely this constellation that might shorten reading times in one condition and prolong it in the other condition that allows an effect of verb semantics to surface in the reading times.

Finally, the reading times for inanimate relativeclause-internal noun phrases were longer than the reading times for animate relative-clause-internal noun phrases. Since this comparison is made across different sets of nouns, this effect does not allow a clear theoretical interpretation.

The main effect of Animacy of Subject at the auxiliary and the two positions following it cannot be interpreted straightforwardly, because of the interaction at these positions: the reading times in the object relative clauses with an inanimate subject were longer than the reading times in all three other conditions. However, inspection of the means at the auxiliary and the two words following it shows that reading times in the subject relative clauses with inanimate subject (condition SubjRC-Inanimate Subject), in which no reanalysis was made according to our account, are also longer than the reading times in the conditions with an animate subject (conditions SubjRC-Animate Subject and ObjRC-Animate Subject). At the auxiliary and the two words following the auxiliary, the reading times were significantly longer in subject relative clauses with an inanimate subject (condition SubjRC-Inanimate Subject) than in the subject relative clauses with an animate subject (condition SubjRC-Animate Subject), though the effect was only marginal at the auxiliary (auxiliary: 452 vs. 416, 95\% confidence interval $\pm 38 \mathrm{~ms}$; first word after the auxilia- ry: 363 vs. $340,95 \%$ confidence interval $\pm 17 \mathrm{~ms}$; second word after the auxiliary: 325 vs. $303 \mathrm{~ms}, 95 \%$ confidence interval $\pm 14 \mathrm{~ms})$. However, the past participles differ semantically and hence the whole relative clause has a different meaning. Moreover, the past participles in the subject relative clauses with an inanimate subject (condition SubjRC-Inanimate Subject) were both longer and less frequent. Therefore, one must be careful in interpreting this main effect. Importantly, however, this does not affect the critical interaction between Animacy of Subject and Clause Type. This interaction reflects longer reading times in condition ObjRC-Inanimate Subject than in condition SubjRC-Inanimate Subject, i.e., in a within-item comparison, while no such difference is found in the within-item comparison of condition SubjRC-Animate Subject and ObjRC-Animate Subject.

\section{Experiment 3}

There are several aspects of the self-paced reading task that make it an unnatural way of reading. First, the need to press a button to read each word might interfere with the reading process. As a consequence, reading times are unusually long in self-paced reading. Second, the readers cannot make regressions to earlier parts of the sentence. Both aspects are absent in an eye-tracking experiment, which makes it a more natural reading task. Therefore, in Experiment 3 eye tracking was used to measure the reading behavior. We report three dependent measures. As a measure of immediate processing we used the forward reading time (Vonk \& Cozijn, 2003). We also used the total-pass reading time (Murray, 2000; also referred to as the regression path duration: Konieczny, 1996; Konieczny, Hemforth, Scheepers, \& Strube, 1997) and the percentage of regressions. To enable comparison of our measures with other commonly used measures, in the appendices we also present the results of the first-pass reading time and the total reading time. Figures with descriptive results are presented in Appendix A; the statistical results are presented in Appendix B.

\section{Method}

\section{Participants}

Thirty-two students of the University of Nijmegen participated in the experiment. They were native speakers of Dutch. All had normal or corrected to normal vision. They were paid for their participation. They had not participated in Experiments 1 and 2.

\section{Materials and design}

Forty-eight sets of four sentences were used in the experiment: Sixteen new sets of sentences were added to the 32 sets that were used in Experiment 2. The 
conditions were the same as in Experiment 2 (see Table 3 ). The animate nouns were on average 8.46 letters long, and the inanimate nouns were on average 8.04 letters long. This difference was not significant: $F<1$. The mean $\log$ frequency in the CELEX Dutch database was 2.97 for the animate nouns and 2.77 for the inanimate nouns $(F<1)$. As in the materials of Experiment 2 the past participles in the animate subject conditions and in the inanimate subject conditions could not be matched completely in length and frequency. The past participles of the 48 sets had a mean length of 8.35 letters in the animate subject condition, and of 9.54 letters in the inanimate subject condition, respectively. This difference was significant: $F(1,47)=10.29, p<.005$. The past participles in the animate subject condition were more frequent than the past participles in the inanimate subject condition: the mean log frequency was 3.05 and 2.34 , respectively $(F(1,47)=21.38, p<.001)$.

In 24 of the items, the subject was singular and the object was plural. In the other 24 items the subject was plural and the object was singular. The 48 experimental items were mixed with 48 unrelated filler sentences. Verification statements were included after $25 \%$ of experimental and filler trials (see (13) for an example).

The 48 experimental sentences and 48 fillers were pseudo-randomly divided into two blocks of trials. Four experimental versions were constructed in the same way as in Experiment 2. Each block was preceded by six practice trials. At the beginning of the experiment there was a practice block of 14 trials. The practice items had constructions similar to the ones used in the experiment. The layout of the sentences was the same as in Experiment 2.

\section{Apparatus}

The materials were presented on a PC monitor. The distance between the participants' eyes and the monitor was $85 \mathrm{~cm}$, making one degree of visual angle equivalent to 4.4 character positions.

The eye movements were recorded using an AmTech ET3 eye tracker. Both $X$ and $Y$ positions were collected with a sample frequency of $200 \mathrm{~Hz}$, and a spatial resolution of $.25^{\circ}$. Only the movements of the right eye were recorded, although vision was binocular. Head movements were restricted by the use of a chin and forehead rest, and a bite-bar.

\section{Procedure}

Before the experiment each participant was informed about the purpose of the apparatus. Then the apparatus was adjusted, so that the participant would be seated as comfortably as possible, and the bite bar was prepared. The calibration procedure for the eye tracker was explained and the participants were instructed to read the sentences so that they understood the meaning and would be able to verify statements about them.

Each block started with a calibration, and there was an additional calibration in the middle of each experimental block. The first three trials after each calibration were practice trials. Before every four sentences a short recalibration was performed to correct for possible shifts in head position after the calibration. Each trial started with an asterisk indicating where the next sentence would start. The participants were instructed to look at the asterisk, and then to press the button, which made the sentence appear on the screen. When the participants had finished reading the sentence, they pressed the button again, which, in most cases, started the next trial. In $25 \%$ of the trials the sentence was followed by a verification statement. The participants had to judge whether the statement was consistent with the content of the preceding sentence by pressing one of two buttons. This button press started the next trial.

The participants were instructed not to blink when reading the sentences. They were allowed to blink when they were reading a statement or fixating an asterisk.

\section{Results}

In Experiment 3, we did not analyze the sentences word by word, but combined words into regions. The regions that were analyzed are given in square brackets in (17).

(17) In het dorp[ zijn][ de wandelaars,]die[ de rots][ weggerold][ hebben,][ het gesprek] van de dag. In the town[ are][ the hikers,] ]that [ the rock][ rolled-away][ have,][ the talk] of the day.

The antecedent noun phrases and the relative-clauseinternal noun phrases were analyzed as a whole. The relative pronoun was not analyzed, because it received almost no fixations. Instead, an additional analysis was performed on the region consisting of the relative pronoun and the relative-clause-internal noun phrase. The last region we analyzed was the region consisting of the first two words following the relative clause $(\operatorname{Aux}+1)$.

If participants skip a region frequently, the participant and item means in a condition may be based on only a few or even only one observation. This can cause extreme values to have a strong effect on the results. Therefore, we decided only to include a subjects' mean in the statistical analyses if this mean was based on at least 4 out of the maximally possible 12 observations. In the item analysis the item mean was included if the mean was based on at least three out of the maximally possible eight observations. This procedure affected primarily the region that contained the auxiliary. At other 
regions only the forward reading times (see below) were affected. $^{3}$

Three measures were computed. The first was the forward reading time. The forward reading time consists of the time spent at a region in first pass (including saccades and regressions within the region), if that region is left with a progressive saccade. We chose this measure, because regressive saccades out of the region often are preceded by shorter reading times than progressive saccades out of the region (Vonk \& Cozijn, 2003). Thus, when a reader makes a regression because there is a problem in understanding the sentence, the reading time preceding that regression will in fact be shorter, instead of longer, due to the processing problem. Hence, these cases are excluded in the forward reading time.

The second measure was the total-pass reading time (Murray, 2000; cf. Konieczny, 1996; Konieczny et al., 1997), defined as the time spent in a region in first pass before leaving that region to the right, plus the time spent in regressing to earlier parts of the sentence, including saccades. We included the duration of the saccades between successive fixations within a region in our measures (excluding saccades into and out of a region) because it has been shown that processing does not stop during saccades (cf. Irwin, 1998; Vonk \& Cozijn, 2003). The third measure was the percentage of cases in which a regression to an earlier region was made in first-pass reading. In Appendices $\mathrm{A}$ and $\mathrm{B}$, we also report the results of the first-pass reading time, which is the time spent at a region in first-pass, before the region is left either with a progressive saccade or with a regressive saccade, and the total reading time, which is the sum of all fixations in a region.

For each of the regions defined above, two two-way analyses of variance were computed, one with participants $(F 1)$ and one with items $(F 2)$ as the random variable. The factors included in the analyses were Animacy of Subject (animate subject vs. inanimate subject) and Clause Type (subject relative clause vs. object relative clause). The results of the statistical tests for the critical regions are presented in Table 5. In the following, we will discuss the effects that were significant in the participant and item analyses.

\footnotetext{
${ }^{3}$ The exclusion of data, together with missing data due to the fact that readers often skip a region may result in length differences even if the materials are identical at the region of interest. Therefore, we computed the mean length of the regions for the trials that were actually involved in the analyses. Apart from the length difference at the past participle that is discussed in the materials section, there were no length differences in any of the regions. Moreover, for the forward reading times, we did an analysis on the residual reading times. This analysis yielded the same pattern of results as for the forward reading times.
}

In the forward reading time, all cases in which a region was left with a regressive saccade were excluded (1146 cases, 17\%). Then, cases in which the forward reading time was shorter than $50 \mathrm{~ms}$ and longer than $4000 \mathrm{~ms}$ were excluded (5 cases). From the remaining cases those that were more than two standard deviations away from a participant's and item's mean for a given position (13 cases) were excluded. The results of the forward reading time are presented in Fig. 3.

Total-pass reading times that were shorter than $50 \mathrm{~ms}$ and longer than $4000 \mathrm{~ms}$ ( 8 cases) were excluded from further analysis. From the remaining total-pass reading times those that were more than two standard deviations away from a participant's and item's mean for a given position in a condition (48 cases) were excluded $(0.8 \%$ of the data points).

Participants read the verification statements carefully. On average, they gave the correct answer to $92 \%$ of these statements (lowest score 74\%, standard deviation 5\%).

The results of the total-pass reading time and the percentage of regressions are presented in Fig. 4. The most important finding from Experiment 2 was the interaction of Animacy of Subject and Clause Type that started at the past participle and lasted until the first word after the auxiliary. This interaction was replicated in the present experiment, at the auxiliary and at the region immediately following the auxiliary. In the following we will discuss the regions from left to right, starting with the antecedent noun phrase and ending with the first region after the clause-final auxiliary. For all main effects and interactions we will first report the forward reading time, then the percentage of regressions and finally the totalpass reading time. If, in one of the measures, a main effect or interaction is not reported, this means that the effect or interaction was not significant.

\section{Antecedent noun phrase}

At the antecedent noun phrase, there was an interaction of Animacy of Subject and Clause Type in the forward reading time and in the total-pass reading time. This interaction is in fact an effect of animacy: The animate nouns were read faster than the inanimate nouns, both in the sentences with animate subjects and in the sentences with inanimate subjects (forward reading time: 48 and $44 \mathrm{~ms}$, respectively, $95 \%$ confidence interval \pm 26 ; total-pass reading time: 89 and $43 \mathrm{~ms}$, respectively, 95\% confidence interval \pm 32 ).

\section{Past participle}

At the past participle, there was a main effect of Animacy of Subject in all measures. As in Experiment 2, the past participles in sentences with animate subjects (conditions SubjRC-Animate Subject and ObjRCAnimate Subject) were on average read faster than those in sentences with inanimate subjects (conditions 
Table 5

Analysis of variance results of Experiment 3

\begin{tabular}{|c|c|c|c|c|c|c|c|c|}
\hline \multirow[t]{2}{*}{ Region } & \multirow[t]{2}{*}{ Source of variance } & \multirow[t]{2}{*}{ Measure } & \multicolumn{2}{|c|}{ By participants } & \multicolumn{2}{|c|}{ By items } & \multicolumn{2}{|c|}{$\operatorname{Min} F^{\prime}$} \\
\hline & & & $d f$ & $F 1$ & $d f$ & $F 2$ & $d f$ & $\min F^{\prime}$ \\
\hline \multirow[t]{9}{*}{ Antecedent } & \multirow[t]{3}{*}{ AniO } & forward rt & 1,21 & 1.72 & 1,33 & 1.98 & 1,50 & .92 \\
\hline & & $\%$ regressions & 1,31 & .62 & 1,47 & .30 & 1,76 & .20 \\
\hline & & total-pass $r t$ & 1,31 & .02 & 1,47 & .00 & 1,77 & .01 \\
\hline & \multirow[t]{3}{*}{$\mathrm{CT}$} & forward $r t$ & 1,21 & .03 & 1,33 & .29 & 1,25 & .03 \\
\hline & & $\%$ regressions & 1,31 & .01 & 1,47 & .03 & 1,51 & .00 \\
\hline & & total-pass $r t$ & 1,31 & 1.75 & 1,47 & 1.88 & 1,74 & .91 \\
\hline & \multirow[t]{3}{*}{$\mathrm{AniO} \times \mathrm{CT}$} & forward rt & 1,21 & $10.24^{* *}$ & 1,33 & $4.88^{*}$ & 1,53 & $3.30^{\dagger}$ \\
\hline & & $\%$ regressions & 1,31 & .46 & 1,47 & 1.07 & 1,56 & .43 \\
\hline & & total-pass $r t$ & 1,31 & $14.99^{* *}$ & 1,47 & $5.66^{*}$ & 1,73 & $4.11^{*}$ \\
\hline \multirow[t]{9}{*}{$R C$-internal } & \multirow[t]{3}{*}{ AniO } & forward rt & 1,24 & .03 & 1,46 & .02 & 1,69 & .01 \\
\hline & & $\%$ regressions & 1,31 & 1.08 & 1,46 & .07 & 1,52 & .07 \\
\hline & & total-pass rt & 1,31 & .90 & 1,46 & 1.81 & 1,60 & .60 \\
\hline & \multirow[t]{3}{*}{$\mathrm{CT}$} & forward rt & 1,24 & .577 & 1,46 & .36 & 1,70 & .22 \\
\hline & & $\%$ regressions & 1,31 & .05 & 1,46 & .00 & 1,63 & .01 \\
\hline & & total-pass $r t$ & 1,31 & .00 & 1,46 & .23 & 1,34 & .01 \\
\hline & \multirow[t]{3}{*}{$\mathrm{AniO} \times \mathrm{CT}$} & forward rt & 1,24 & .16 & 1,46 & .10 & 1,69 & .06 \\
\hline & & $\%$ regressions & 1,31 & .01 & 1,46 & .08 & 1,39 & .01 \\
\hline & & total-pass rt & 1,31 & 1.51 & 1,46 & .39 & 1,66 & .31 \\
\hline \multirow[t]{9}{*}{ Past participle } & \multirow[t]{3}{*}{ AniO } & forward rt & 1,30 & $19.50^{* *}$ & 1,46 & $12.96^{* *}$ & 1,76 & $7.79^{* *}$ \\
\hline & & $\%$ regressions & 1,31 & 2.75 & 1,47 & $4.43^{*}$ & 1,65 & 1.70 \\
\hline & & total-pass $r t$ & 1,31 & $13.57^{* *}$ & 1,47 & $13.64^{* *}$ & 1,75 & $6.80^{*}$ \\
\hline & \multirow[t]{3}{*}{$\mathrm{CT}$} & forward rt & 1,30 & 2.00 & 1,46 & 1.03 & 1,75 & .68 \\
\hline & & $\%$ regressions & 1,31 & .27 & 1,47 & .09 & 1,72 & .07 \\
\hline & & total-pass rt & 1,31 & .51 & 1,47 & .13 & 1,67 & .10 \\
\hline & \multirow[t]{3}{*}{$\mathrm{AniO} \times \mathrm{CT}$} & forward rt & 1,30 & .69 & 1,46 & .01 & 1,47 & .01 \\
\hline & & $\%$ regressions & 1,31 & .61 & 1,47 & .87 & 1,68 & .35 \\
\hline & & total-pass rt & 1,31 & $3.19^{\dagger}$ & 1,47 & 2.60 & 1,77 & 1.43 \\
\hline \multirow[t]{9}{*}{ Auxiliary } & \multirow[t]{3}{*}{ AniO } & forward $r t$ & 1,22 & $26.69^{* *}$ & 1,24 & $3.89^{\dagger}$ & 1,31 & $3.40^{\dagger}$ \\
\hline & & $\%$ regressions & 1,26 & 1.50 & 1,32 & 1.28 & 1,58 & .69 \\
\hline & & total-pass rt & 1,26 & $16.79^{* *}$ & 1,32 & $8.95^{* *}$ & 1,56 & $5.84^{*}$ \\
\hline & \multirow[t]{3}{*}{$\mathrm{CT}$} & forward rt & 1,22 & .79 & 1,24 & .78 & 1,46 & .39 \\
\hline & & $\%$ regressions & 1,26 & $3.26^{\dagger}$ & 1,32 & $5.15^{*}$ & 1,52 & 2.00 \\
\hline & & total-pass $r t$ & 1,26 & $4.14^{*}$ & 1,32 & $6.81^{*}$ & 1,52 & 2.58 \\
\hline & $\mathrm{AniO} \times \mathrm{CT}$ & forward rt & 1,22 & 2.47 & 1,24 & $6.77^{*}$ & 1,37 & 1.81 \\
\hline & & $\%$ regressions & 1,26 & $6.68^{*}$ & 1,32 & $13.43^{* *}$ & 1,49 & $4.46^{*}$ \\
\hline & & total-pass $r t$ & 1,26 & $10.70^{* *}$ & 1,32 & $15.28^{* *}$ & 1,54 & $6.29^{*}$ \\
\hline Auxiliary +1 & AniO & forward rt & 1,28 & $7.93^{* *}$ & 1,37 & 1.56 & 1,50 & 1.30 \\
\hline & & $\%$ regressions & 1,30 & $20.42^{* *}$ & 1,43 & $22.13^{* *}$ & 1,70 & $10.62^{* *}$ \\
\hline & & total-pass rt & 1,30 & $27.41^{* *}$ & 1,43 & $16.06^{* *}$ & 1,72 & $10.12^{* *}$ \\
\hline & $\mathrm{CT}$ & forward rt & 1,28 & .30 & 1,37 & .96 & 1,45 & .23 \\
\hline & & $\%$ regressions & 1,30 & $6.80^{*}$ & 1,43 & $6.39^{*}$ & 1,71 & $3.29^{\dagger}$ \\
\hline & & total-pass rt & 1,30 & $6.28^{*}$ & 1,43 & $11.58^{* *}$ & 1,59 & $4.07^{*}$ \\
\hline & $\mathrm{AniO} \times \mathrm{CT}$ & forward rt & 1,28 & 2.38 & 1,37 & .41 & 1,49 & .35 \\
\hline & & $\%$ regressions & 1,30 & $9.39^{* *}$ & 1,43 & $5.01^{*}$ & 1,72 & $3.27^{\dagger}$ \\
\hline & & total-pass rt & 1,30 & $8.06^{* *}$ & 1,43 & $10.73^{* *}$ & 1,66 & $4.60^{*}$ \\
\hline
\end{tabular}

Note. AniO, Animacy of Object; CT, Clause Type.

${ }_{* *}^{*} p<.05$.

${ }^{* *} p<.01$.

$\dagger p<.10$.

SubjRC-Inanimate Subject and ObjRC-Inanimate Subject), which were on average longer and less frequent (forward reading times $285 \mathrm{~ms}$ vs. $322 \mathrm{~ms}, 95 \%$ confi- dence interval \pm 17 ; total-pass reading times $315 \mathrm{~ms}$ vs. $372 \mathrm{~ms}, 95 \%$ confidence interval \pm 32 ; percentage of regressions: $7 \%$ vs. $10 \%, 95 \%$ confidence interval $\pm 3 \%$ ). 


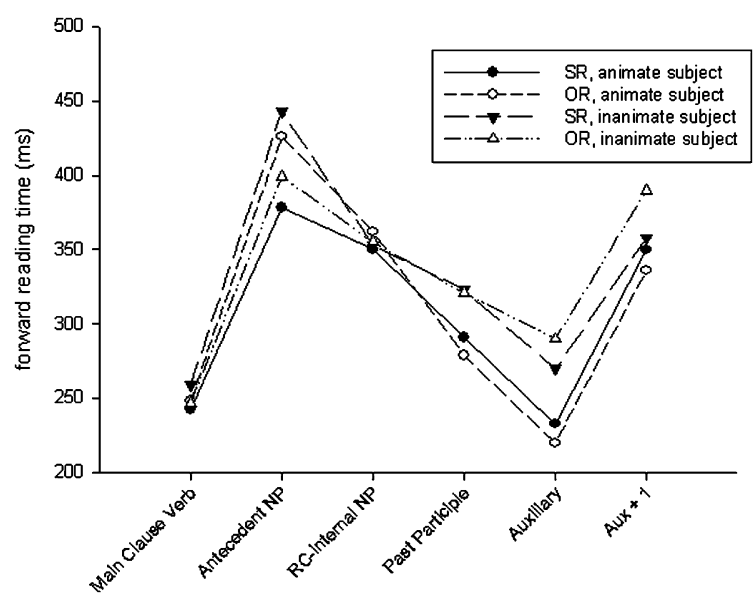

Fig. 3. Forward reading times (in $\mathrm{ms}$ ) in Experiment 3 as a function of Clause Type and animacy of subject. SR, subject relative clause; OR, object relative clause.
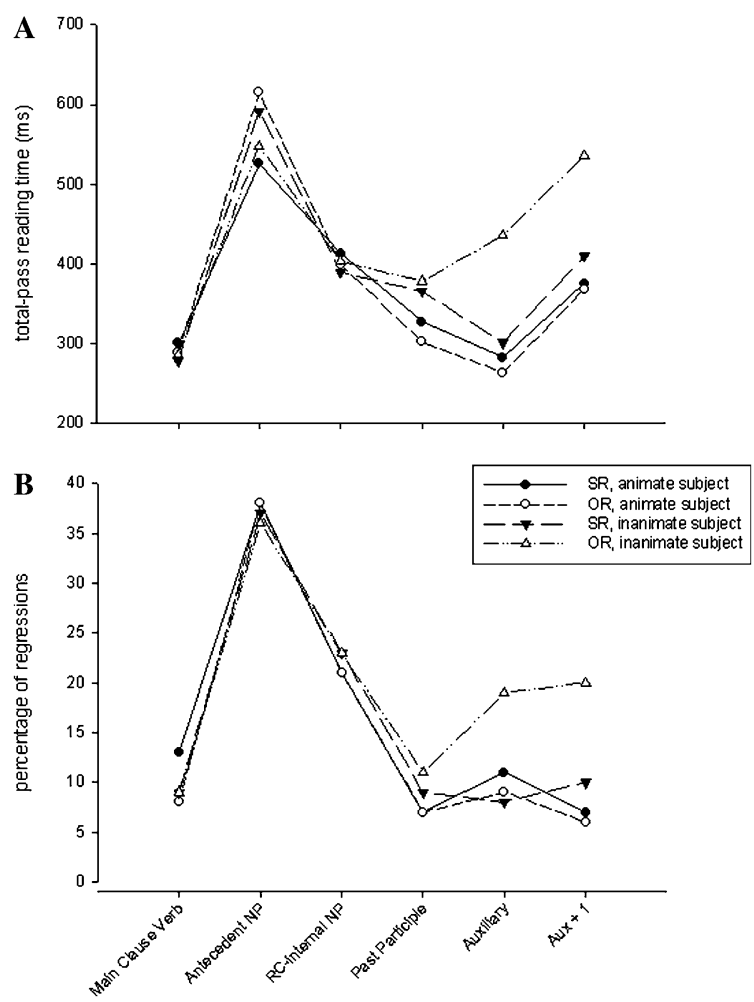

Fig. 4. Total-pass reading times (in ms; A) and percentages of regressions (B) in Experiment 3 as a function of Clause Type and animacy of subject. SR, subject relative clause; OR, object relative clause.

\section{Auxiliary}

At the auxiliary there was a main effect of Animacy of Subject in the forward reading time (though marginal $(p=.06)$ in the item analysis), the first-pass reading time, and the total-pass reading time. There also was a main effect of Clause Type in the percentage of regressions and in the total-pass reading time. Most importantly, there also was an interaction of Animacy of Subject and Clause Type in all measures. In the conditions with an animate subject (conditions SubjRC-Animate Subject and ObjRC-Animate Subject) the effect of Clause Type was not significant in any of the measures (forward reading times: $233 \mathrm{~ms}$ vs. $220 \mathrm{~ms}$, $95 \%$ confidence interval $\pm 21 \mathrm{~ms}$; percentage of regressions: $11 \%$ vs. $9 \%, 95 \%$ confidence interval $\pm 5 \%$; total-pass reading times $375 \mathrm{~ms}$ vs. $380 \mathrm{~ms}$; $95 \%$ confidence inter$\mathrm{val} \pm 50 \mathrm{~ms})$. In the conditions with an inanimate subject (conditions SubjRC-Inanimate Subject and ObjRC-Inanimate Subject), reading times were longer in object relative clauses than in subject relative clauses in the percentage of regressions (19\% vs. $8 \% ; 95 \%$ confidence interval $\pm 5 \%$ ) and in the total-pass reading time (435 ms vs. $301 \mathrm{~ms} ; 95 \%$ confidence interval $\pm 50 \mathrm{~ms}$ ), but not in the forward reading times $(270 \mathrm{~ms}$ vs. $289 \mathrm{~ms} ; 95 \%$ confidence interval $\pm 21 \mathrm{~ms})$.

The results of the forward reading time at the auxiliary may be influenced by the fact that readers often only had one fixation at the verb cluster (past participle plus auxiliary). This fixation was often located towards the right edge of the past participle. Readers probably were able to process the number information at the auxiliary during that fixation, and hence regressions from the past participle may be based on the processing of the entire verb cluster. In that case, fixations at the auxiliary that follow these regressions are in fact secondpass reading. Therefore, we performed an additional analysis at the auxiliary, in which not only the cases were excluded in which there was a regression from the auxiliary, but also the cases in which there had been a regression from the past participle (extended forward reading time; see Vonk \& Cozijn, 2003). In this analysis there was a significant effect of Animacy of Subject $(F 1(1,18)=19.60, \quad p<.01 ; \quad F 2(1,20)=6.24, \quad p<.05 ;$ $\left.\operatorname{Min} F^{\prime}(1,31)=4.73, \quad p<.05\right), \quad$ and an interaction between Animacy of Subject and Clause Type, though marginal in the item analysis $(F 1(1,18)=4.27, p=.05$; $\left.F 2(1,21)=4.02, p=.06 ; \operatorname{Min} F^{\prime}(1,39)=.39, p=.16\right)$. There was no effect in the conditions with an animate subject (conditions SubjRC-Animate Subject and ObjRC-Animate Subject, 229 and $210 \mathrm{~ms}$, respectively), but the effect in the conditions with an inanimate subject (conditions SubjRC-Inanimate Subject and ObjRC-Inanimate Subject, 247 and $284 \mathrm{~ms}$, respectively) was significant. The $95 \%$ confidence interval for these differences was \pm 24 .

The interaction at the auxiliary replicates the pattern of results in Experiment 1. As expected, there was no effect of clause type in the conditions with an animate subject, whereas there was an effect in the conditions with an inanimate object. Note that these comparisons 
are made between sentences in which exactly the same words were used (including the past participle), and hence this difference between sentences with an animate subject on the one hand, and an inanimate subject on the other hand cannot be caused by the length and frequency differences of the past participles.

$A u x+1$. At the region immediately following the auxiliary, the pattern of results was similar to the pattern at the auxiliary. There was a significant effect of Animacy of Subject in all measures, an effect of Clause Type in the percentage of regressions and a significant interaction in the percentage of regressions and the total-pass reading time. Again, in the conditions with an animate subject (conditions SubjRC-Animate Subject and ObjRC-Animate Subject) there was no difference (percentage of regressions: $7 \%$ vs. $6 \%, 95 \%$ confidence interval $\pm 4 \%$; total-pass reading time: $375 \mathrm{~ms}$ vs. $368 \mathrm{~ms}$, $95 \%$ confidence interval $\pm 57 \mathrm{~ms}$ ), but in the conditions with an inanimate subject (conditions SubjRC-Inanimate Subject and ObjRC-Inanimate Subject) reading times were significantly longer in the object relative clauses than in the subject relative clauses in the percentage of regressions ( $20 \%$ vs. $10 \%$; $95 \%$ confidence interval $\pm 4 \%$ ) and in the total-pass reading time $(536 \mathrm{~ms}$ vs. $410 \mathrm{~ms} ; 95 \%$ confidence interval $\pm 57 \mathrm{~ms}$ ).

There were no other main effects or interactions at any of the regions. The additional analysis at the region consisting of the relative pronoun and the relativeclause-internal noun phrase did not yield any significant results.

The results of the first-pass reading time (see Appendices $\mathrm{A}$ and $\mathrm{B}$ ) are similar to those of the forward reading time. The pattern of results of the total reading time is similar to the pattern of results of the total-pass reading time, with the exception that the interaction of Animacy and Clause Type is visible already at the relative-clause-internal noun phrase and the past participle. This is probably the result of regressions from the auxiliary region and later regions.

\section{Discussion}

The results of Experiment 3 confirm the pattern of results of Experiment 2. At the auxiliary and at the region following it, the critical interaction of Animacy of Subject and Clause Type was obtained. When the subject of the relative clause was animate, and the object inanimate (conditions SubjRC-Animate Subject and ObjRC-Animate Subject in Table 3), there were no differences in any of the three measures throughout the relative clause. When the subject was inanimate, and the object animate (conditions SubjRC-Inanimate Subject and ObjRC-Inanimate Subject), reading times in the object relative clause were longer. This effect was first visible at the auxiliary, and was also found at the region following the auxiliary. In contrast to Experiment 2, the effect was not visible at the past participle. Thus, although Experiment 2 showed that the semantic information from the past participle was sufficient to initiate a reanalysis, this was not visible in the data of Experiment 3. We will return to this in General discussion.

As pointed out above, the length and frequency difference between the past participles in conditions SubjRC-Animate Subject and ObjRC-Animate Subject on the one hand, and the past participles in SubjRC-Inanimate Subject and ObjRC-Inanimate Subject on the other hand, cannot be the cause of the critical interaction of Animacy of Subject and Clause Type. This was confirmed by an additional analysis. For this analysis, we selected a subset of 26 items in which the past participles were matched for $\log$ frequency $(F(1,25)=2.12$, $p=.16)$ and length $(F(1,25)=1.45, p=.24)$. This analysis yielded the same pattern of results as the analysis with the entire item set in all regions, except for the past participle. At the past participle, the reduced item set now also shows a significant interaction of Animacy of Subject and Clause Type for the total-pass reading time $(F 1(1,31)=3.90, \quad p=.05 ; \quad F 2(1,25)=8.06, \quad p<.01$; $\left.\operatorname{Min} F^{\prime}(1,53)=2.63 ; p=.11\right)$, similar to the results of Experiment 2. In the conditions with an inanimate subject (conditions SubjRC-Inanimate Subject and ObjRCInanimate Subject) reading times were significantly longer in the object relative clauses than in the subject relative clauses ( $354 \mathrm{~ms}$ vs. $392 \mathrm{~ms}$ ). In the conditions with an animate subject (conditions SubjRC-Animate Subject and ObjRC-Animate Subject) there was no effect (334 ms vs. $301 \mathrm{~ms}$ ). The $95 \%$ confidence interval for these differences was \pm 36 .

With respect to the reading times at the relativeclause-internal noun phrase and the antecedent noun phrase, there were differences between Experiment 2 and Experiment 3. In Experiment 2, we found longer reading times in the relative clause at the inanimate noun phrases than at the animate noun phrases, but this effect was not replicated in Experiment 3. In Experiment 3 there was an effect of animacy at the antecedent noun phrase. At that position, reading times were longer for inanimate noun phrases than for animate noun phrases (see also Mak et al., 2002; Weckerly \& Kutas, 1999).

In Experiment 2, we found the critical interaction already at the past participle. In Experiment 3, there is no immediate effect on the past participle; the interaction was only found in the total reading time. We do not have a clear explanation for this difference.

\section{General discussion}

Mak et al. (2002) found that there was no difference in reading times between subject and object relative clauses when the subject of the relative clause is animate 
and the object is inanimate. However, their data do not give conclusive evidence about the precise way animacy influences the parsing process. In the following we will discuss the data from the present experiments in the light of the two broad classes of theories that were presented in the introduction.

Syntax-first theories claim that initially readers opt for the subject relative clause reading on the basis of syntactic parsing preferences. Hence a non-syntactic factor, such as animacy, will not influence this first stage of parsing.

According to the Active Filler Strategy (Frazier, 1987), on reading the relative pronoun, readers in all cases analyze the clause as a subject relative clause on the basis of the alternative gap-positions on which the filler (the relative pronoun) can be placed. This implies that animacy can only influence the parsing process during a reanalysis. However, the data from Mak et al. (2002) do not show any evidence of such a reanalysis in object relative clauses with an inanimate antecedent and an animate relative-clause-internal noun phrase. Hence, this result does not support the Active Filler Strategy. However, the absence of a delay in reading times in these relative clauses compared to their subject relative counterparts, may be caused by the fact that the reanalysis that the reader has to make is spread over a long region, in the sentences of Mak et al. (2002) from the antecedent up to the auxiliary.

The results from the present experiments make it possible to evaluate this interpretation. Experiment 1 , in which we tested sentences with two inanimate noun phrases, shows that it is not the inanimacy of the antecedent per se that affects processing of relative clauses. If that were the case, readers should opt for an object relative clause, when both noun phrases are inanimate. However, in this experiment we found the same pattern of results as in relative clauses with two animate noun phrases. Hence, the animacy effect must be due to a difference in animacy between the two noun phrases. Moreover, Experiments 2 and 3 show that a difference in animacy does not by itself lead to a reanalysis either, since in that case prolonged reading times should be found at or after the relative-clause-internal noun phrase when it is animate. Hence, the region at which the reanalysis is made is restricted to the verb cluster. In Experiments 2 and 3, in the conditions with an animate subject (conditions SubjRC-Animate Subject and ObjRC-Animate Subject) the difference is not even descriptively in the direction predicted by a reanalysis account. Therefore, the data do not support an account in terms of a semantically driven reanalysis of an initial syntactic analysis. Hence, theories that claim that the choice for an initial analysis of the relative clause is not affected by animacy (e.g., Frazier,
1987) are not supported by the data of the present experiments.

Hence, the possibility that non-syntactic information is used already in the earliest stages of processing, as claimed by another class of theories, should be considered as a serious option. For models that assume a modular architecture, with the syntactic module operating separately from other modules, this implies that only those models that assume that there are concurrent processes at different levels can explain the data (e.g., Hemforth, Konieczny, \& Scheepers, 2000).

The data are fully compatible with models that posit that language processing involves multiple interacting constraints (e.g., MacDonald et al., 1994; Trueswell et al., 1994). In the following, we will discuss how the different factors that influence relative clause processing may lead to the pattern of results found in our experiments. With respect to the influence of animacy, Experiment 1 shows that the animacy effect must be the result of a difference in animacy between the two entities in the relative clause. Hence, if animacy guides the initial choice of the subject of the relative clause, this choice cannot be made before the relative-clauseinternal noun is read.

In the introduction to Experiment 2, we proposed that there is an additional factor that influences the choice for one of the two noun phrases as the subject of the relative clause. Since the relative clause is a statement about the antecedent, the antecedent is the topic of the relative clause (cf. Kuno, 1976; Lambrecht, 1988; Van Valin, 1996). Readers tend to choose the entity that is the topic of a sentence or clause as the subject. For the relative clauses this means that there is a tendency to choose the antecedent noun phrase as the subject.

This can be related to the Topichood Hypothesis (Mak, 2001; Mak, Vonk, \& Schriefers, in preparation). The Topichood Hypothesis claims that the choice of one of the entities as the subject of the relative clause is determined by the topicworthiness of the entities. Other things being equal, the antecedent of the relative clause is more topicworthy than the relative-clause-internal noun phrase, since it is the topic of the relative clause.

However, there are other factors that determine the topicworthiness of an entity. One of those is whether a noun phrase is a full noun phrase or a pronominal noun phrase. Personal pronouns refer to entities that are topical. Evidence for the influence of this factor comes from experiments in which the relative-clause-internal noun phrase is pronominal (Gordon, Hendrick, \& Johnson, 2001; Mak, 2001; Mak et al., in preparation; Warren \& Gibson, 2002; but see Kaan, 2001). Other evidence is provided by Fox and Thompson (1990) in an analysis of corpus data. They found that non-human antecedent noun phrases that refer to a new entity in the discourse tended to occur with object relative clauses. The subject 
of these relative clauses often was a pronoun referring to a discourse topic. Fox and Thompson explained this phenomenon using the concept of grounding, relating a new entity to the discourse. The relative clauses were used to link the antecedent, a new entity, to the discourse by explicitly relating it to a discourse topic.

The topicworthiness of an entity is determined by more than just the question whether or not it is the sentence topic. Animacy is another factor that contributes to the topicworthiness of an entity. Animate entities are more topicworthy than inanimate entities. Thus, animacy and topicality are in fact both related to the broader notion of topicworthiness. These two factors can also be found in the hierarchy of properties that Van Valin and Wilkins (1996) introduce. In this hierarchy there are two dimensions, which correspond closely to an animacy hierarchy and a topicality hierarchy. The position of the noun phrases on the topicality and animacy scale determines whether a particular noun phrase has what they call the effector role. This role subsumes both animacy and topicality.

However, topicworthiness does not only apply to effects at the sentence level. An entity that is the discourse topic is more topicworthy than an entity that is not. Hence, the Topichood Hypothesis makes the prediction that the processing difficulty of object relative clauses should be reduced when the relative-clause-internal noun phrase is the discourse topic compared to when it is not, even if it is a full noun phrase.

Our explanation of the results of the experiments in this paper implies a comparison between the two noun phrases with respect to topicworthiness. This comparison determines which of the noun phrases is the most likely candidate for the subject function of the relative clause. This is reminiscent of Gordon et al. (2001), who use a similarity-based account to explain why the processing difficulty of object relative clauses is reduced when the subject of this relative clause is a pronoun, as in (18).

(18) The banker that you praised climbed the mountain.

(19) The banker that the lawyer praised climbed the mountain

According to Gordon et al., the difficulty readers have with object relative clauses as in (19) comes from the fact that these relative clauses require two noun phrases to be stored in memory and subsequently accessed whereas in English this is not the case for subject relative clauses. The difficulty of accessing the two representations is reduced when they are dissimilar, as in (18), compared to when they are similar, as in (19). Hence, less processing difficulty is found in (18) than in (19). The explanation of the difference in processing difficulty between subject and object rela- tive clauses in terms of the number of noun phrases to be stored in memory does not hold for Dutch relative clauses, however, because in Dutch the requirement of holding two noun phrases in memory would be present in both subject and object relative clauses, since both subject and object relative clauses are verbfinal. Hence, the explanation by Gordon et al. for the difficulty of (19) does not explain the similar difficulty found in Dutch and other verb-final languages. Conversely, if we apply our account to the Gordon et al. data, the lack of difficulty in (18) is explained by the Topichood Hypothesis. Because of the fact that pronouns typically refer to entities that are topical, they are likely candidates for the syntactic function of subject, which eliminates the difficulty of object relative clauses with a pronominal relative-clause-internal noun phrase.

Experiments 2 and 3 show that there are at least two factors that interact in the assignment of the subject and object functions: animacy and topicality. Both factors can eventually be subsumed under topicworthiness. The results of Experiment 2 suggest that a third factor, the semantic content of the verb, might also play a role. The semantic content of the past participle in our materials always made clear which of the two competitors is the most likely subject of the clause. The early effect at the past participle in the conditions with an inanimate subject in Experiment 2 (conditions SubjRC-Inanimate Subject and ObjRC-Inanimate Subject) showed that, at least in word-by-word reading, the semantic content of the past participle can initiate a reanalysis. In Experiment 3 the effect was not significant at the past participle in the full item set, but it was significant in the reduced item set.

The unrestricted race model (Traxler et al., 1998; Van Gompel et al., 2005, 2001) claims that the different analyses of a syntactic ambiguity are engaged in a race and the structure that is completed fastest is adopted. When an ambiguity occurs at a particular word, only major category information of this word is used in the construction of the alternative analyses. However, any information that occurred prior to it can influence the construction of the alternative structures. If there is no strong preference for one of the alternative analyses, the processor adopts either analysis approximately half of the time, and therefore a reanalysis can occur in both alternatives. In the relative clauses, the ambiguity starts at the relative pronoun. At that point the animacy information from the antecedent can be used in the race between the two alternatives. It is possible, therefore, that when the antecedent is inanimate, the parser more often adopts the object relative clause-reading than when the antecedent is animate. This should mean that these conditions should have elevated reading times compared to subject relative clauses with an animate antecedent, but shorter reading times compared to object relative clauses with an animate 
antecedent. This is not in line with the pattern of results in the experiments: Most notably, object relative clauses with an inanimate antecedent (ObjRC-Animate Subject) did not have longer reading times than subject relative clauses with an animate antecedent (SubjRC-Animate Subject).

Our approach implies that readers sometimes do not immediately commit themselves to an analysis of a sentence in case of ambiguity. An alternative to the hypothesis that readers in some cases do not assign syntactic functions is the possibility that both structures are computed, but no choice is made between the alternatives. For example, Gibson (1998) posits that the processor is ranked parallel: Two alternative structures that differ only little in processing difficulty are maintained in parallel.

In our approach, readers sometimes have to keep the relative pronoun and the relative-clause-internal noun phrase in memory without assigning them the syntactic functions of subject and object. In principle this may be viewed as costly, but a corpus analysis (Mak et al., 2002) shows that when readers use the difference in animacy in their choice between a subject and an object relative clause, they will need to make a reanalysis in fewer cases than when they always initially adopt a subject relative clause reading. The corpus study shows that animacy is an important factor in the distribution of the different types of relative clauses. Mak et al. selected all relative clauses with a full noun phrase as the antecedent and a relative-clause-internal full noun phrase from a corpus consisting of Dutch newspaper texts. There were 286 relative clauses of this type in the corpus. The results are given in Table 6 .

The frequencies with which the different relative clause types occur in the corpus show that relative clauses that should lead to a reanalysis according to the present account are infrequent. In relative clauses in which both the subject and the object are animate noun phrases readers have to make a reanalysis in an object relative clause, but not in a subject relative clause. In the corpus, there were 21 subject relative clauses of this type and no object relative clauses.

There is no difference in processing difficulty between subject and object relative clauses that have an animate subject and an inanimate object (conditions SubjRC-Animate Subject and ObjRC-Animate Subject in our experiments; 189 cases in the corpus). Both types of relative clause were frequently present in the corpus (119 subject relative clauses and 70 object relative clauses).

When the subject of the relative clause is inanimate and the object is animate (conditions SubjRC-Inanimate Subject and ObjRC-Inanimate Subject; 15 cases in the corpus), there is no processing difficulty in subject relative clauses, whereas object relative clauses are very difficult. Indeed, among the few relative clauses with this animacy configuration there are more subject relative clauses (13) than object relative clauses (2).

Finally, according to the strategy we proposed, in relative clauses with two inanimate noun phrases, readers opt for a subject relative clause reading, and hence they have to make a reanalysis in object relative clauses. Again, whereas there are many subject relative clauses of this type (53 cases), there are only 8 object relative clauses.

If readers have a strategy in which they always initially analyze a relative clause as a subject relative clause, as proposed by syntax-first strategies, they have to make a reanalysis in $28 \%$ of the sentences from the Dutch corpus. However, when readers indeed employ the strategy we outlined above, the percentages of cases in which they have to make a reanalysis drops to only $4 \%$ of the sentences. Since making a reanalysis is costly, this strategy would be very useful to the reader.

The match between the corpus data and the processing results suggests that a tuning account is also compatible with the data. Tuning accounts claim that processing preferences are driven by the frequency of occurrence of particular sentence structures (e.g., Mitchell, Cuetos, Corley, \& Brysbaert, 1995). On the basis of the present data one cannot decide between a tuning account and the Topichood Hypothesis.

Note however, that if readers are sensitive to the differences in frequency found in the corpus study, this implies that language users are not just sensitive to the frequency of particular syntactic structures, in this case subject and object relative clauses, but rather to the frequency of the two types of relative clauses given the value of variables such as the animacy of the noun phrases involved in the relative clause.

According to the Topichood Hypothesis, discourse structure will also affect the processing preferences for relative clauses. More specifically, when one of the noun phrases of a relative clause is the topic of the preceding

Table 6

Number of subject and object relative clauses as a function of Animacy of the Subject and the Object and Clause Type (adapted from Mak et al., 2002)

\begin{tabular}{lcccc}
\hline & $\begin{array}{c}\text { Animate Subject, } \\
\text { Animate Object }\end{array}$ & $\begin{array}{c}\text { Animate Subject, } \\
\text { Inanimate Object } \\
\text { (Experiments 2 \& 3) }\end{array}$ & $\begin{array}{c}\text { Inanimate Subject, } \\
\text { Animate Object } \\
\text { (Experiments 2 \& 3) }\end{array}$ & $\begin{array}{c}\text { Inanimate Subject, } \\
\text { Inanimate Object } \\
\text { (Experiment 1) }\end{array}$ \\
\hline Subject relative clause & 21 & 119 & 13 & 53 \\
Object relative clause & 0 & 70 & 2 & 8 \\
\hline
\end{tabular}


discourse, there should be a preference for assigning this noun phrase the syntactic function of subject in the relative clause. Such effects of discourse are not predicted by a tuning account, since it is restricted to the relative frequency of occurrence of particular sentence types.

The topichood hypothesis subsumes animacy under topicworthiness. However, one could view animacy also as a syntactic factor, because, for example, some languages explicitly reflect animacy in their case marking system. The Topichood Hypothesis predicts that manipulations of topichood that do not imply a manipulation of animacy should yield similar results as the animacy manipulation used in the present study. Such a pure effect from a topichood manipulation, without an animacy manipulation, would therefore provide additional clear evidence for early effects of non-syntactic factors in sentence processing. Furthermore, it should be noted that, in sentence processing research, animacy is commonly treated as a semantic variable (see also Introduction).

To sum up, the Topichood Hypothesis provides an account for the pattern of results found in the present experiments as well as for the commonly reported preference for subject relative clauses and other results on relative clause processing. According to the Topichood Hypothesis the reader opts for one of the noun phrases in the relative clause as the subject on the basis of topicworthiness, which subsumes both animacy and topicality of the antecedent. The interplay of these two factors leads to the pattern of results in the present experiments. The Topichood Hypothesis also provides additional predictions that can be tested empirically. The difficulty of object relative clauses should be affected by the relative-clauseinternal noun phrase being a full noun phrase or a pronoun (Gordon et al., 2001). Moreover, even when the relative-clause-internal noun phrase is a full noun phrase, parsing of object relative clauses should be easier when the referent of the full noun phrase is the discourse topic compared with when it is a new entity. Future research has to show whether the predictions are actually supported by corresponding experiments.

\section{Appendix A}

First-pass reading time (in ms, A) and total reading time (in $\mathrm{ms}, \mathrm{B}$ ) in Experiment 3 as a function of clause type and animacy of subject. SR, subject relative clause; OR, object relative clause.
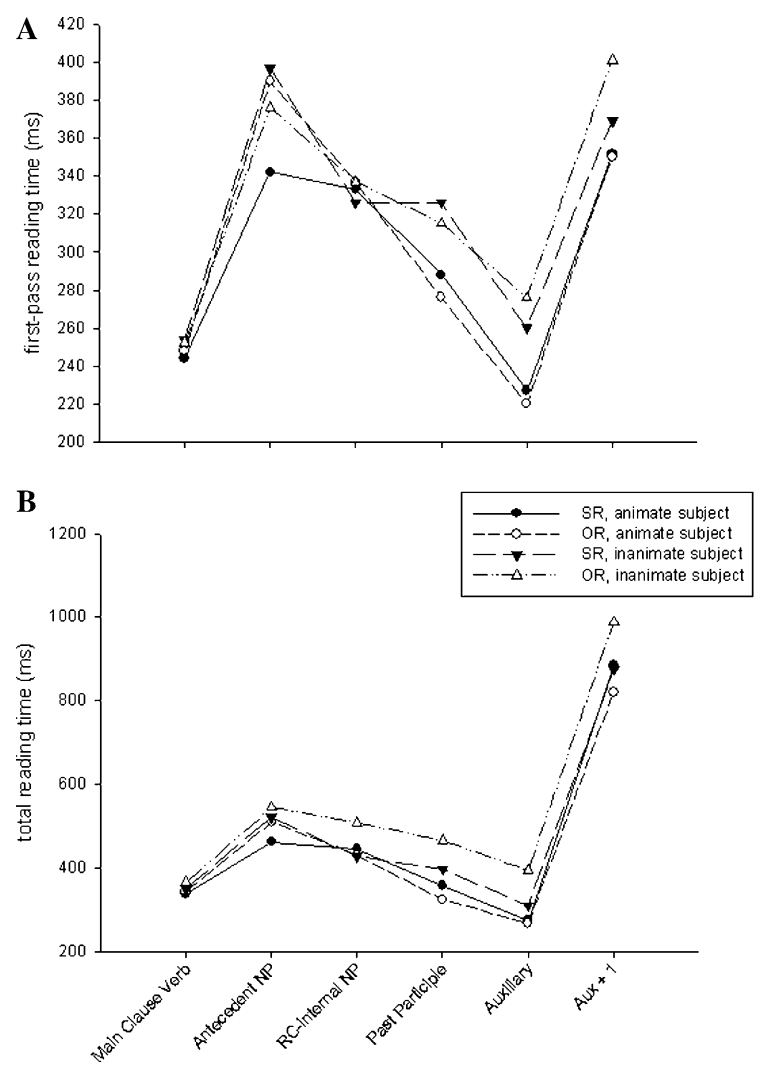

\section{Appendix B}

Analysis of variance results of Experiment 3: first-pass reading times and total reading times

\begin{tabular}{|c|c|c|c|c|c|c|c|c|}
\hline \multirow[t]{2}{*}{ Region } & Source of variance & \multirow[t]{2}{*}{ Measure } & \multicolumn{2}{|c|}{ By participants } & \multicolumn{2}{|c|}{ By items } & \multicolumn{2}{|c|}{$\operatorname{Min} F^{\prime}$} \\
\hline & & & $d f$ & $F 1$ & $d f$ & $F 2$ & $d f$ & $\min F^{\prime}$ \\
\hline \multirow[t]{6}{*}{ Antecedent noun phrase } & AniO & first-pass rt & 1,31 & 2.02 & 1,47 & $2.79^{\dagger}$ & 1,68 & 1.17 \\
\hline & & total rt & 1,31 & $8.52^{* *}$ & 1,47 & $5.29^{*}$ & 1,78 & 3.26 \\
\hline & $\mathrm{CT}$ & first-pass $r t$ & 1,31 & 1.49 & 1,47 & .43 & 1,69 & .33 \\
\hline & & total $r t$ & 1,31 & $4,15^{*}$ & 1,47 & $3.27^{\dagger}$ & 1,77 & 1.83 \\
\hline & $\mathrm{AniO} \times \mathrm{CT}$ & first-pass $r t$ & 1,31 & $9.51^{* *}$ & 1,47 & $3.16^{\dagger}$ & 1,71 & 2.37 \\
\hline & & total $r t$ & 1,31 & .80 & 1,47 & .19 & 1,66 & .15 \\
\hline
\end{tabular}


Appendix B (continued)

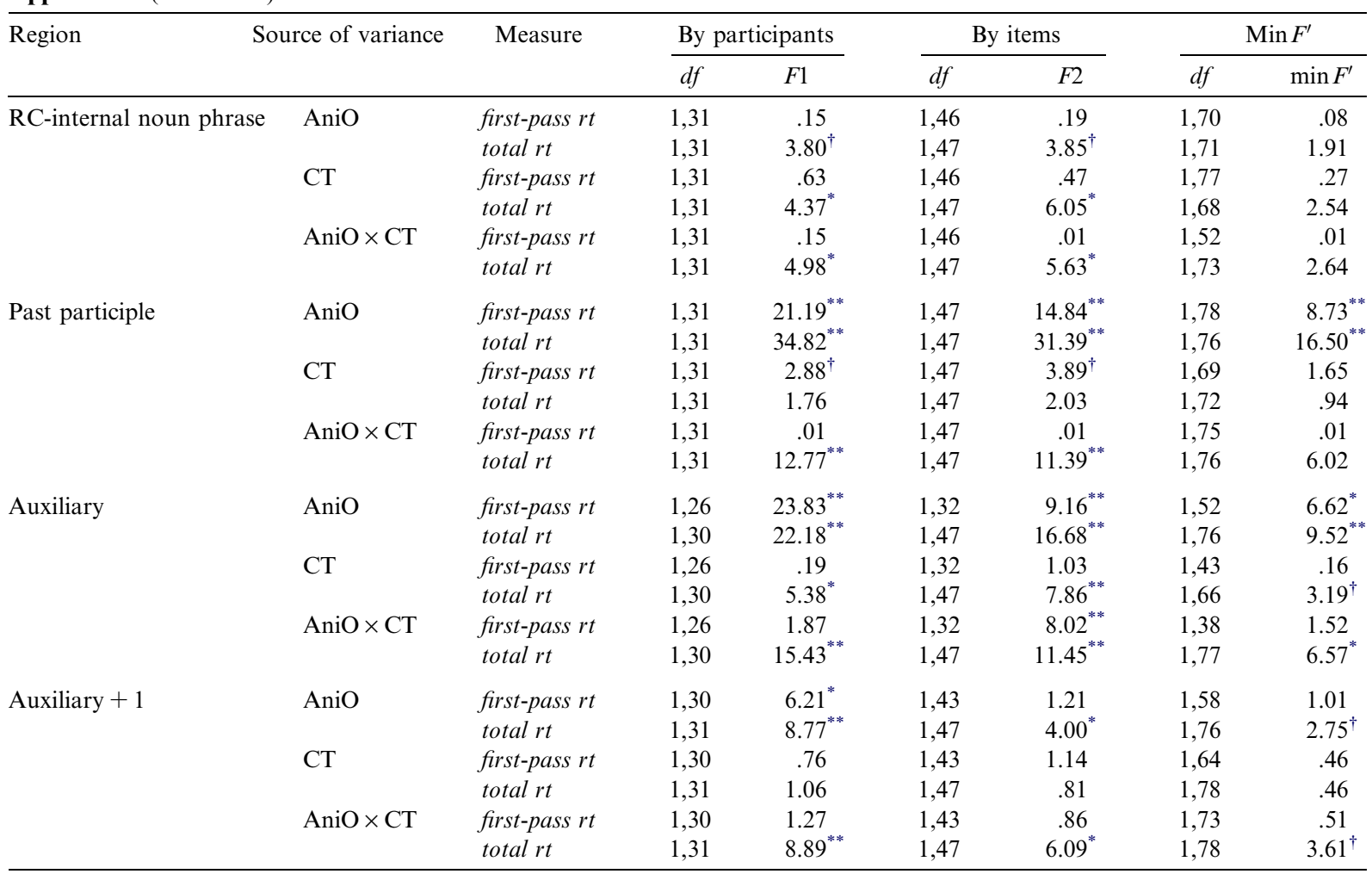

Note. AniO, Animacy of Object; CT, Clause Type.

${ }^{*} p<.05$.

${ }^{* * *} p<.01$.

$\dagger^{\dagger} p<.10$.

\section{Appendix C}

Condition means in the experiments reported in this paper

\begin{tabular}{|c|c|c|c|c|}
\hline & SR & OR & & \\
\hline \multicolumn{5}{|l|}{ Experiment 1} \\
\hline Main Clause Verb & 347 & 338 & & \\
\hline Determiner 1 & 300 & 304 & & \\
\hline Antecedent Noun & 523 & 505 & & \\
\hline Relative Pronoun & 367 & 356 & & \\
\hline Determiner & 283 & 288 & & \\
\hline RC-internal Noun & 393 & 408 & & \\
\hline Verb & 497 & 529 & & \\
\hline Verb +1 & 358 & 395 & & \\
\hline \multirow[t]{3}{*}{ Verb +2} & 306 & 335 & & \\
\hline & \multicolumn{2}{|c|}{ Animate Subject } & \multicolumn{2}{|c|}{ Inanimate Subject } \\
\hline & $\overline{\mathrm{SR}}$ & OR & SR & OR \\
\hline \multicolumn{5}{|l|}{ Experiment 2} \\
\hline Main Clause Verb & 361 & 363 & 353 & 361 \\
\hline Determiner 1 & 320 & 324 & 319 & 325 \\
\hline Antecedent Noun & 490 & 536 & 502 & 507 \\
\hline
\end{tabular}


Appendix C (continued)

\begin{tabular}{llllll}
\hline & \multicolumn{2}{c}{ Animate Subject } & & \multicolumn{2}{c}{ Inanimate Subject } \\
\cline { 2 - 3 } \cline { 5 - 6 } & SR & OR & & SR & OR \\
\hline Relative Pronoun & 376 & 379 & & 370 & 371 \\
Determiner & 314 & 310 & & 307 & 315 \\
RC-internal Noun & 387 & 347 & & 345 & 372 \\
Past Participle & 367 & 367 & 364 & 443 \\
Auxiliary & 416 & 400 & & 452 & 557 \\
Auxiliary +1 & 340 & 342 & 363 & 426 \\
Auxiliary +2 & 303 & 313 & 325 & 346
\end{tabular}

Forward reading time

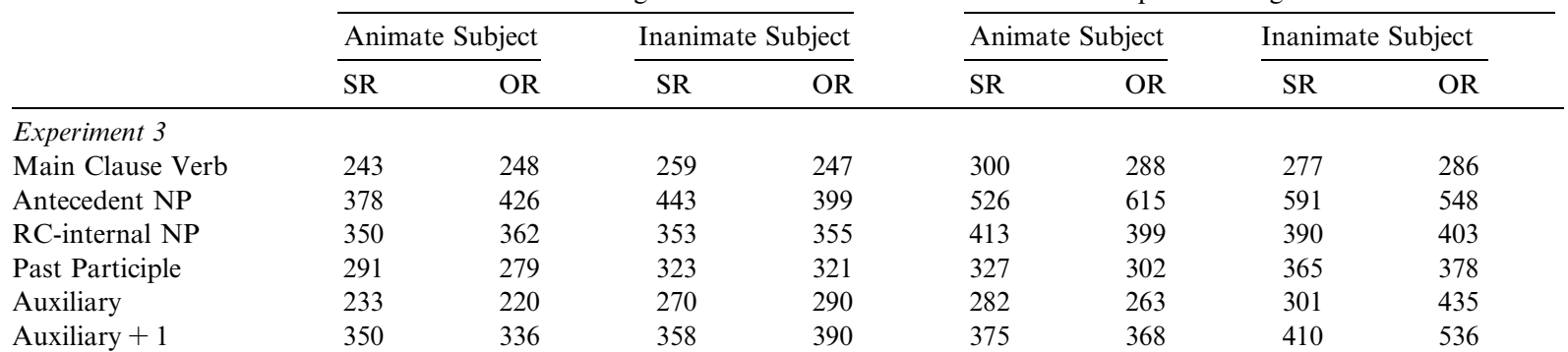

Total reading time

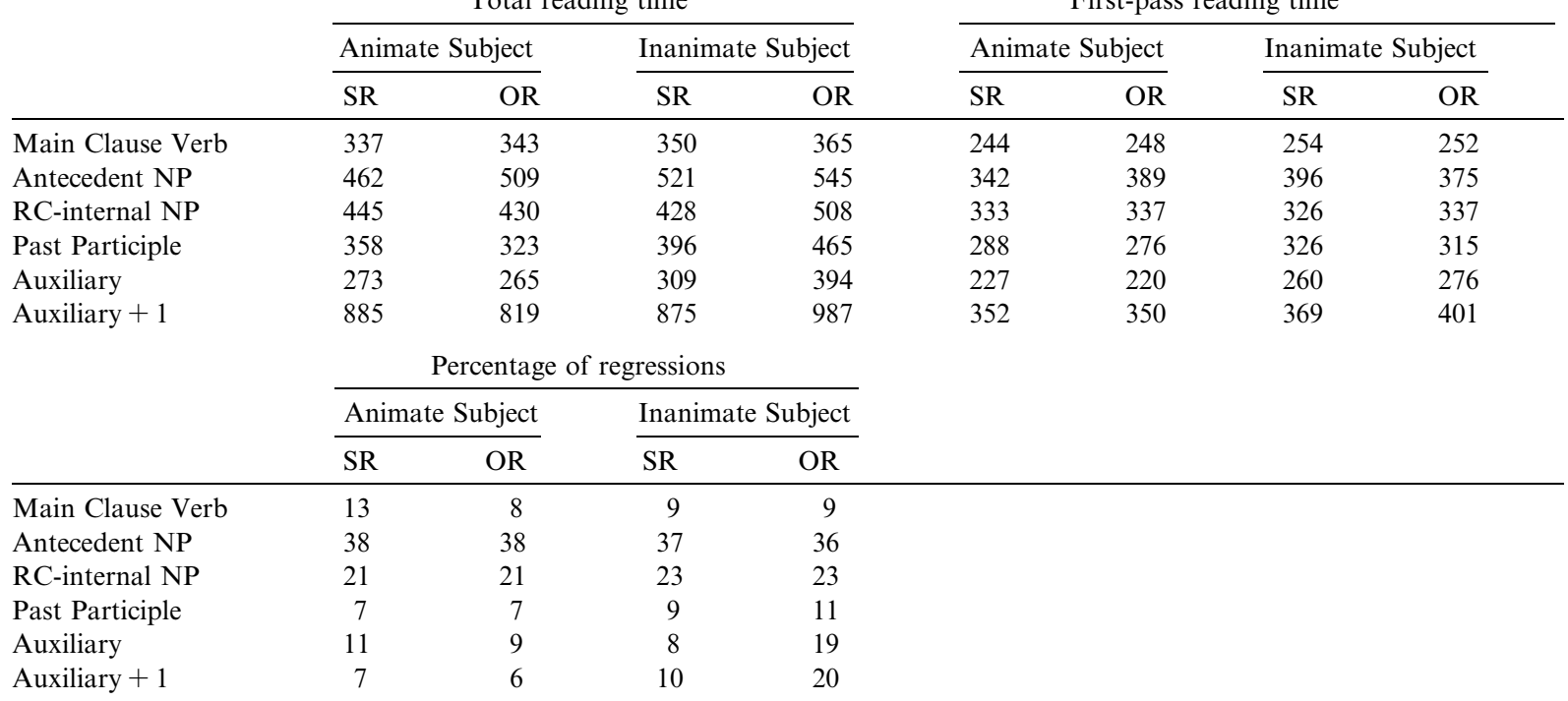

Note. SR, Subject Relative Clause; OR, Object Relative Clause.

\section{References}

Baayen, R. H., Piepenbrock, R., \& Gulikers, L. (1995). The CELEX lexical database (CD-ROM), Linguistic Data Consortium, University of Pennsylvania, Philadelphia, PA.

Clark, H. H. (1973). The language-as-fixed-effect fallacy: A critique of language statistics in psychological research. Journal of Verbal Learning and Verbal Behavior, 12, 335-359.

Clifton, C., Jr., Traxler, M. J., Taha Mohamed, M., Williams, R. S., Morris, R. K., \& Rayner, K. (2003). The use of thematic role information in parsing: Syntactic processing autonomy revisited. Journal of Memory and Language, 49, 317-334.
Ford, M. (1983). A method for obtaining measures of local parsing complexity throughout sentences. Journal of Verbal Language and Verbal Behavior, 22, 203-218.

Fox, B. A., \& Thompson, S. A. (1990). A discourse explanation of the grammar of relative clauses in English conversation. Language, 66, 297-316.

Frauenfelder, U., Segui, J., \& Mehler, J. (1980). Monitoring around the relative clause. Journal of Verbal Learning and Verbal Behavior, 19, 328-337.

Frazier, L. (1987). Syntactic processing: Evidence from Dutch. Natural Language and Linguistic Theory, 5, 519-559.

Gibson, E. (1998). Linguistic complexity: Locality of syntactic dependencies. Cognition, 68, 1-76. 
Gordon, P. C., Hendrick, R., \& Johnson, M. (2001). Memory interference during language processing. Journal of Experimental Psychology: Learning, Memory, and Cognition, 27, 1411-1423.

Hemforth, B., Konieczny, L., \& Scheepers, C. (2000). Modifier attachment: Relative clauses and coordinations. In B. Hemforth \& L. Konieczny (Eds.), German sentence processing, pp. 161-186.

Holmes, V. M., \& O'Regan, J. K. (1981). Eye fixation patterns during the reading of relative-clause sentences. Journal of Verbal Learning and Verbal Behavior, 20, 417-430.

Irwin, D. E. (1998). Lexical processing during saccadic eye movements. Cognitive Psychology, 36, 1-27.

Kaan, E. (2001). Effects of NP type on the resolution of wordorder ambiguities. Journal of Psycholinguistic Research, 5, 529-547.

King, J., \& Just, M. A. (1991). Individual differences in syntactic processing: The role of working memory. Journal of Memory and Language, 30, 580-602.

King, J. W., \& Kutas, M. (1995). Who did what and when? Using word- and clause- level ERPs to monitor working memory usage in reading. Journal of Cognitive Neuroscience, 7, 376-395.

Konieczny, L. (1996). Human sentence processing: A semanticsoriented parsing approach. Freiburg: University of Freiburg. IIG-Berichte 3/96.

Konieczny, L., Hemforth, B., Scheepers, C., \& Strube, G. (1997). The role of lexical heads in parsing: Evidence from German. Language and Cognitive Processes, 12, 307-348.

Kuno, S. (1976). Subject, theme, and the speakers' empathy-a reexamination of relativization phenomena. In C. N. Li (Ed.), Subject and topic (pp. 417-444). New York: Academic Press.

Lambrecht, K. (1988). There was a farmer had a dog: Syntactic amalgams revisited. In Proceedings of the Fourteenth Annual Meeting of the Berkeley Linguistics Society (pp. 319-339). California: Berkely.

MacDonald, M. C., Pearlmutter, N. J., \& Seidenberg, M. S. (1994). Lexical nature of syntactic ambiguity resolution. Psychological Review, 101, 676-703.

Mak, W. M. (2001). Processing relative clauses: Effects of pragmatic, semantic, and syntactic variables. Unpublished doctoral dissertation, Nijmegen, the Netherlands.

Mak, W. M., Vonk, W., \& Schriefers, H. (2002). The influence of animacy on relative clause processing. Journal of Memory and Language, 47, 50-68.

Mak, W. M., Vonk, W., \& Schriefers, H. (in preparation). Discourse structure and relative clause processing.

Masson, E. J., \& Loftus, G. R. (2003). Using confidence intervals for graphically based data interpretation. Canadian Journal of Experimental Psychology, 57, 203-220.

Mecklinger, A., Schriefers, H., Steinhauer, K., \& Friederici, A. D. (1995). Processing relative clauses varying on syntactic and semantic dimensions: An analysis with event-related potentials. Memory \& Cognition, 23, 477-494.

Mitchell, D. C., Cuetos, F., Corley, M. M. B., \& Brysbaert, M. (1995). Exposure-based models of human parsing: Evidence for the use of coarse-grained (nonlexical) statistical records. Journal of Psycholinguistic Research, 24, 469-488.

Murray, W. (2000). Sentence processing: Issues and measures. In A. Kennedy, R. Radach, D. Heller, \& J. Pynte (Eds.), Reading as a perceptual process (pp. 649-664). Oxford: Elsevier.

Raaijmakers, J. G. W., Schrijnemakers, J. M. C., \& Gremmen, F. (1999). How to deal with the "language-as-fixed-effect fallacy": Common misconceptions and alternative solutions. Journal of Memory and Language, 41, 416-426.

Schriefers, H., Friederici, A. D., \& Kühn, K. (1995). The processing of locally ambiguous relative clauses in German. Journal of Memory and Language, 34, 499-520.

Traxler, M. J., Morris, R. K., \& Seely, R. E. (2002). Processing subject and object relative clauses: Evidence from eye movements. Journal of Memory and Language, 47, 69-90.

Traxler, M. J., Pickering, M. J., \& Clifton, C. Jr., (1998). Adjunct attachment is not a form of lexical ambiguity resolution. Journal of Memory and Language, 39, 558-592.

Trueswell, J. C., Tanenhaus, M. K., \& Garnsey, S. M. (1994). Semantic influences on parsing: Use of thematic role information in syntactic ambiguity resolution. Journal of Memory and Language, 33, 285-318.

Van Gompel, R. G., Pickering, M. J., Pearson, J., \& Liversedge, S. P. (2005). Evidence against competition during syntactic ambiguity resolution. Journal of Memory and Language, 52, 284-307.

Van Gompel, R. P. G., Pickering, M. J., \& Traxler, M. J. (2001). Reanalysis in sentence processing: Evidence against current constraint-based and two-stage models. Journal of Memory and Language, 45, 225-258.

Van Valin, R. D. (1996). Toward a functionalist account of socalled extraction constraints. In B. Devriendt, L. Goossens, \& J. van der Auwera (Eds.), Complex structures: $A$ functionalist perspective (pp. 29-60). Berlin: Gruyter.

Van Valin, R. D., \& Wilkins, D. P. (1996). The case for 'effector': Case roles, agents, and agency revisited. In M. Shibatani \& S. A. Thompson (Eds.), Grammatical constructions (pp. 289-322). Oxford: Clarendon Press.

Vonk, W., \& Cozijn, R. (2003). On the treatment of saccades and regressions in eye movement measures of reading time. In J. Hyönä, R. Radach, \& H. Deubel (Eds.), The mind's eye: Cognitive and applied aspects of eye movement research (pp. 291-312). Amsterdam: Elsevier.

Warren, T., \& Gibson, E. (2002). The influence of referential processing on sentence complexity. Cognition, 85, 79-112.

Weckerly, J., \& Kutas, M. (1999). An electrophysiological analysis of animacy effects in the processing of object relative sentences. Psychophysiology, 36, 559-570. 